\title{
Prediction of Relaminarization Effects on Turbine Blade Heat Transfer
}

R.J. Boyle

Glenn Research Center, Cleveland, Ohio

P.W. Giel

QSS Group, Inc., Brook Park, Ohio

Prepared for the

2001 Turbo Expo

cosponsored by the American Society of Mechanical Engineers and the International Gas Turbine Institute

New Orleans, Louisiana, June 4-7, 2001

National Aeronautics and

Space Administration

Glenn Research Center 
Available from

NASA Center for Aerospace Information 7121 Standard Drive

National Technical Information Service 5285 Port Royal Road Springfield, VA 22100

Available electronically at http://gltrs.grc.nasa.gov/GLTRS 


\title{
PREDICTION OF RELAMINARIZATION EFFECTS ON TURBINE BLADE HEAT TRANSFER
}

\author{
R.J. Boyle \\ National Aeronautics and Space Administration \\ Glenn Research Center \\ Cleveland, Ohio 44135 \\ P.W. Giel \\ QSS Group. Inc. \\ Brook Park. Ohio 44142
}

\begin{abstract}
An approach to predicting turhine blade beat transfer when turbulent flow relaminarizes due to strong favorable pressure gradients is described. Relaminarization is more likely to occur on the pressure side of a rotor blade. While stators also have strong farorable pressure gradients. the pressure surface is less likely to becone turbulent at low to moderate Reynolds numbers. Accounting for the effects of relaminarization for blade hrat transfer can substantially reduce the predicted rotor surface heat transfer. This in turn can lead to reduced rotor cooling requirements. Two dimensional midspan Navier-Stokes analyses were done for each of eighteen test cases using eleven different turbulence models. Results showed that including reslaminarization effects generally improved the agresment with experimental data. The results of this work indicate that relatively small changes in rotor shape can be utilized to extend the likelihood of relaminarization to high Reynolds numbers. Predictions showing how rotor blade heat transfer at a high Reyulds number can be reduced through relaminarization are given.
\end{abstract}

\section{Nomenclature}

$\begin{array}{ll}A^{+} & - \text {Near wall damping coefficient } \\ b & - \text { Constant in equation for } A^{+} \\ C_{f} & - \text { Friction factor } \\ C_{\mathrm{LAG}} & - \text { Constant in lag equation } \\ C^{\prime} & - \text { True chord } \\ C_{r} & - \text { Axial chord } \\ D & - \text { Absolute heat transfer difference } \% \\ h & - \text { Heat transfer coefficient } \\ K & - \text { Acceleration parameter. } \mu(d L / d s) /\left(\rho^{2}{ }^{2}\right) \\ H & - \text { Nach number } \\ N u & - \text { Nusselt number } \\ n_{\mathrm{EXP}} & - \text { Number of experinent al data values }\end{array}$

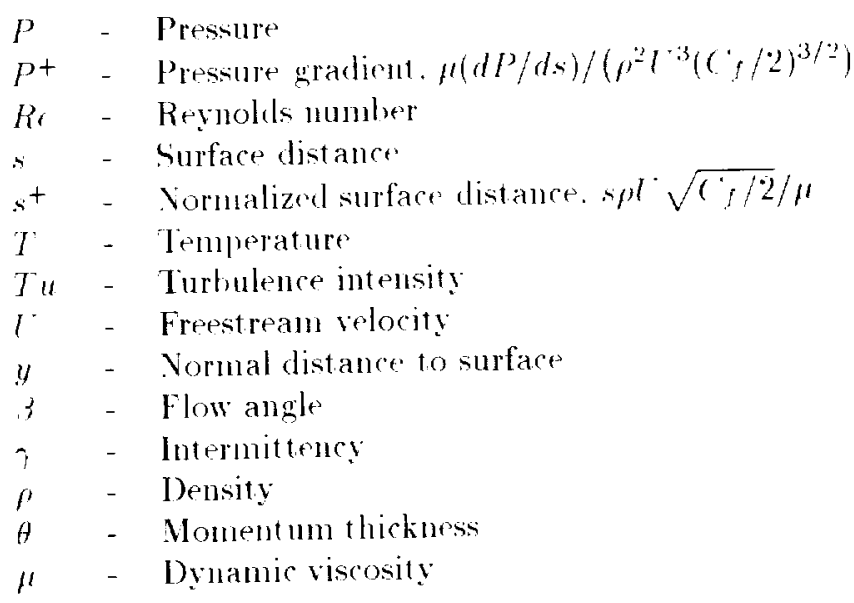

\begin{tabular}{ll} 
Subscripts & \\
\hline CRIT & - Calculated \\
EFF & - Lalue at which relaminarization orcurs \\
EQ & - Effective \\
EXP & - Equilibrium value \\
(AAS & - Experimental \\
LAM & - Laminar \\
S & - Surface distance from stagnation point \\
ST & - Start of transition \\
T & - Total surface distance \\
TCRB & - Turbulent \\
IN & - Cas inlet \\
2 & - Blade row exit
\end{tabular}

\section{INTRODUCTION}

Gas turbine cycle efficiency is improved by increasing rotor inlet temperature and compressor pressure ratio. Higher pressure ratios result in higher coolant temperatures. The higher coolant and higher inlet tem- 
peratures make reducing bhad hed transfer more significant. Designing blades so that the pressure surface bommlary layer is mostly lamimar may significantly reAluce the awrage leat transfer for the ont ire blade. Pla. pressure surface is likely to beecome turbulent due to an adverse pressure gradient close to the leading edge. If this is followed by a strong favorable pressure gradient. the benndary layer is likely to relanimarize. (alculations show that accombting for pressure surface orlaminarization reduces overall blade heat load by approximately 20\% if the turbulonce level is low. However. When the pressure surface is lammar, the hed

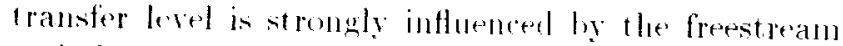

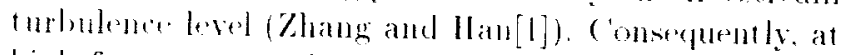
high fresstream turbulence levels the heat transfer teduction may be less. To determine if relaminarization atu be utilized to reduce libde heat transfer accurate lirat tramser predictions at ligh turbulence levels are nexerded.

Relaminarization is more likely to be a fartor for rotor heat transtor than for stator heat transer. Since the inlet relative total velocity is marly twice that of the stator. the peak leading edge invised velocity is also twice as large for the potor. The mininum inviscid pressure surface velocities are about the same for stators and rotors. Rotors have more diffusion, and are. therefore more likely to transition. Relaminarization occurs in a strong favorable pressure gradient. Stators are less likely to lelaminarize. since they are less likely 10 transition close to the leading edge. If the Reynolds numbline is sufficiently high both stators and rotors are likely to transition clone to the leading edge. but relaminarization is not likely to occur. I'sing relaminarization to reduce rotor pressure surface heat transfer was proposed by Brown and Martin[2]. Nicholson et al.[:3] presented atrodynamic and heat transfer results for two rotor geometries. One was designed to relaminarize the pressure surface boundary layer. This hlale shape had lower hoat transfer, and no decrease in aerodymamic efficiency.

Relaminarization will only occur in high favorable pressure gradients. Favorable pressure gradients also delay the onset of transition. Inless the favorable pressure gradients are preceeded by an adverse pressure gradient transition may not occur. especially at low to moderate Reynolds numbers. Calculations for a turbulent boundary layer give a laminar-like boundary layer. when the near wall damping coefficient is a function of the pressure gradient. Different functional forms have been proposed for the pressure gradient effect on the near wall damping coefficient. Cebeci and Smith [4] proposed one relationship, while (rawford and kays[5] proposed anotler. r rawford and liags[5]. and liags and ( raw ford[6] proposed that he local neat wall damping not be a function of the local pressure gradirit. They proposed that the coefficient be lagered to account for the time required to adjust the sublayer thickerss to the pressure gradient change. The two pedrences gave different lag equations. Nicholven el al. [3] and others maintain that a furbulent houndary will relaminarize when the acederation parameter receds a value of approximbtely $3 \times 10^{-1}$. A significant comprttational difference betwern a relaminarized bonmelary layer. and one where the near wall damping coefficient is very large. is that the relaminarizel bomulary layer is laminar. while the other remains turbulent. All modeling which is a function of the intermittency would be different between the two apploaches.

In summary this work addresses the following questions: (1) Is a variable near wall damping confficient appropriate, and if so. is the ('eleci-sinith model more appropriate than the ('rawford and hays model: (2) Should a lag equation be used to calculate either the pressure gradient parameter or the relaminarization paramester: (3) Should relaminarization be forced based on the pressure gradient, or should it be allowed to occus naturally through a variable near wall damping coefficient: and (d) Silould the model to accomm for freestream turbulence effects be applicel for turbulent boundary layers in the presence of strong favorable pressure gradients. These questions are addressed by comparisons with experimental heat transfer data from several sources, to determine which assumptions lead to the best agrement with data. Also. discussed in this work are comparisons with dat a using a $k-\omega$ turbmlence model.

\section{DESCRIPTION of ANALYSIS}

Relaminarization can occur because the near wall damping copfficient..$^{+}$. becomes very large. or it can be forced to occur based on the local value of the pressure gradient parameter. $K$. In all of the results presented. $A^{+}$was taken as a function of the pressure gradient. $P^{+}$. Two similar forms of this relationship are given by Cobeci and Smith[4], and by (rawford and hays[i].

$$
A^{+}=\frac{26 j}{1.0+b P^{+}}
$$

In the cebeci-Smith model $b=11.8$. In the ('rawford and Kays model $b=30.2$ for favorable pressure gradients. $P^{+}<0.0$. and $b=26.1$ otherwise. 


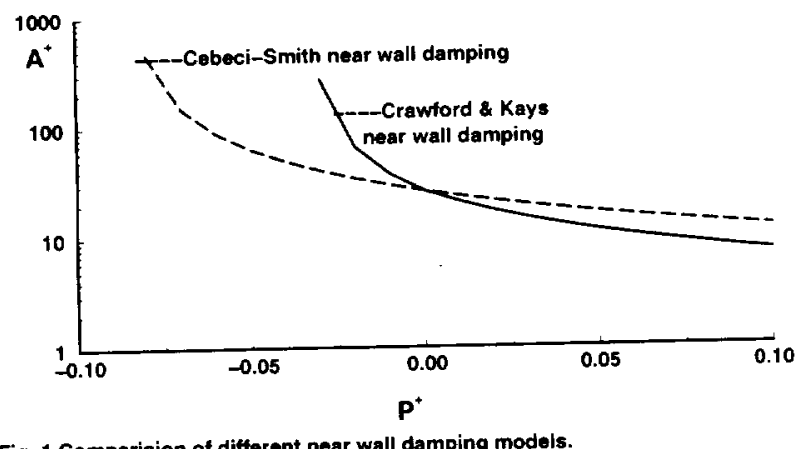

Fig. 1 Comparision of different near wall damping models.

Figure 1 compares the two approaches 10 calculating $A^{+}$. In the favorable pressure gradient region. where relaminarization is likely to occur, the crawforl and hays model provides more near wall damping. ln a negative pressure gradiont the ('rawford and hays model gives a turbulent boundary layer that appears more laminar-like than the Cebeci-Smith model. If the cebeci-smith model gives beter agrement with data. it is possible that a constant value for $A^{+}$of 26 womld give even better data agreement. If the ('rawford and kays model is preferable. a constant value for $A^{+}$would not improve the agreement with clata.

('rawford and kays[5] also recommend that $P^{+}$be replaced by an effective pressure gradient, PEFF. The value of $P_{E F F}^{+}$is calculated from:

$$
\frac{d P_{\mathrm{EFF}}^{+}}{d s^{+}}=-\left(P_{\mathrm{EFF}}^{+}-P^{+}\right) / C_{\mathrm{LAC}}
$$

The recommended value for ( $\mathrm{LAG}$ was 4000 .

An alternative approach to determining the lag in the lear wall damping coefficient is given hy Kays and Crawford[6] as:

$$
\frac{d A_{\mathrm{EFF}}^{+}}{d s^{+}}=-\left(A_{\mathrm{EFF}}^{+}-A_{\mathrm{EQ}}^{+}\right) / \mathrm{C}_{\mathrm{LAC}}
$$

Here $A_{\mathrm{EQ}}^{+}$is the value of $A^{+}$determined from equation 1 using the equilibrium pressure gradient. $P^{+}$. The lag constant. (LAG. recommended value was again 4000.

If $h$ is used as a criteria for relaminarization. it can also be lagged. so that:

$$
\frac{d K_{\mathrm{EFF}}}{d s^{+}}=-\left(h_{\mathrm{EFF}}-h^{*}\right) / C_{\mathrm{LAC}}
$$

For comparison purposes, the same value of 4000 was used for $C_{\text {LAG }}$ when calculating a lagged value for $K$.

Neglecting property variations, $d s^{+} / d s$ is given by:

$$
\frac{d s^{+}}{d s}=\frac{s^{+}}{s}+\frac{s^{+}}{l^{+}} \frac{d l^{v}}{d s}+\frac{s^{+}}{\sqrt{C_{f} / 2}} \frac{d \sqrt{C_{f} / 2}}{d s}
$$

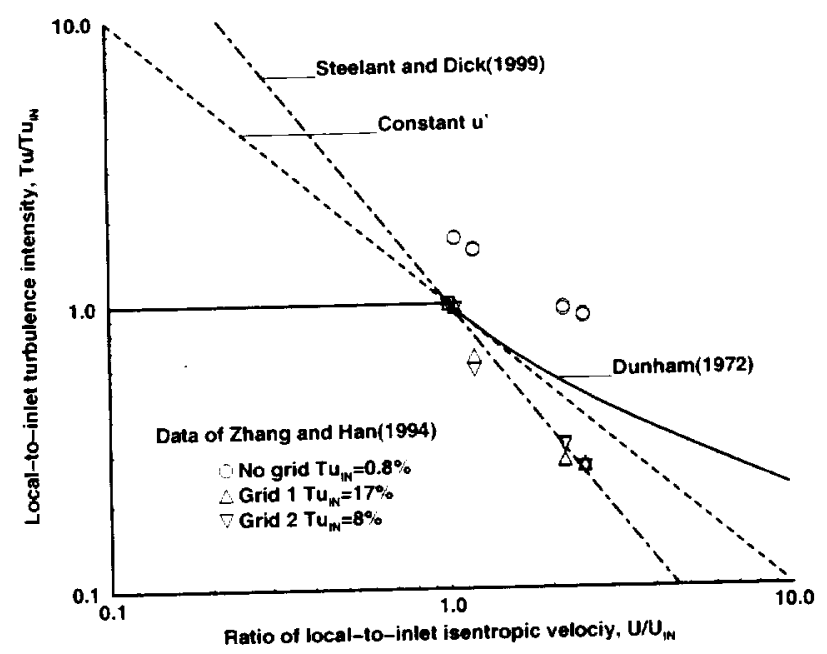

Fig. 2 Tu variation with velocity variation.

While ds is always positive. the right hand side could become negative in an adverse pressure gradient region. When $d s+/ d s$ was negative, it was assmmed that the effective value for the lagged parameter was the equilibrium value.

Mayles[i] transition start criteria was usel. where the Reynolds number at the start of transition is given by:

$$
R_{H-S T}=400 T u^{-\bar{s} / T}
$$

Mayle[T] recommended that a lower limit of $3 \%$ should be used for $T u$ when calculating $R_{A}-\mathrm{ST}$. However. for the cases examined by Boyle and Simon[8]. and for cases examined for this work. better agreement with data was found when the local $T u$ was allowed to decrease below 3\%. The transition length model used was described by Boyle and Simon[8]. It is a modification of the nodel presented by Solomon et al. [9] to account for Mach number effects.

The local turbulent intensity is needed both to determine the start of transition. and to account for increased heat transfer due to freestream t urbulence. Figure 2 illustrates approaches for determining the local freestream turbulence intensity, $T u$. as a function of the local isentropic velocity. The correlation of Dunham[10] limits the freestrean turbulence intensity to the upstream value when the local velocity is less than the upstream value. Another approach. used by Boyle and Simon $[8]$, assumes that the turbulent fluctuations are const ant so that:

$$
T u=T u_{\mathrm{IN}} l{ }_{\mathrm{IN}} / l
$$

Steelant and Dick[11] recommended that the local turbulence intensity be calculated from: 


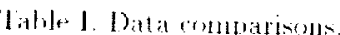

$$
y u=\operatorname{Tun}(1 \mathrm{ix/1})^{3 / 2}
$$

Dumbant sormblion shows the smallest variation in Tu. while the correlation of Sitex ant and Dick showe the largest variation. The data of Zhang and Han[1] show good agreement with the Stevlant and I)ick correlation for velocities greater than the upstream velocity. The local frestroanl velocity. $T^{\prime}$, was calculated from tle local presiture ratio.

The transition models were incorporated into a (puasi-3d Navier-Stokes analysis. (RY(Q:3D). This rods has been docmmented by (hima[12]. and by chima and Yokota[1:3]. (-type grids were generated using the method of Arnone e't al.[1t]. In this approach, the ncar-wall grid is embedded within a coarser grid obtained using the method of Sorenson[15]. For this work dense grids were used. A typical grid was $313 \times 4$ with 196 points on the blade surface. Calculations were for two dimensional Hows. and comparisons were made for midspan heat transfer.

An algebraic turbulent edely viscosity was used for most of the predictions. The one used is the molel deseribed hy (hima of al.[16]. An algebraic model was used as a baseline for two reasons. First. it has heen shown by Ameri and Arnone[17], and by Chima[18] that algebraic models of this type predict turbine blade surface heat transfer as accurately as two equation models. Second, the modifications to algebraic model to account for variable near wall damping. relaminarization, and freestrean turbulence effects on laminar heat transfer are more straightforward. In addition, heat transfer distributions were calculated using the $k-\alpha$ turbulence model described by Chima[18].

Because frestream turbulence was high for the cases examined. the Smith and Kuethe[19] model was used to account for the effects of freestream turbulence on the laminar flow. The augmented laminar viscosity is:

$$
\mu_{\mathrm{LAM}}=\mu_{\mathrm{CAS}}+(1-\eta) 0.164 \rho y T^{\prime} u l
$$

where $y$ is the normal distance from the blade, and MaAs is the molecular viscosity. This model is turned off for turbulent flow using the $1-\gamma$ term. It was generally found that augmenting the turbulence viscosity when the flow was fully turbulent resulted in poorer

\begin{tabular}{|c|c|c|c|c|c|c|}
\hline Solleres & label & $3 x$ & $.11:$ & $\begin{array}{l}R+2 \\
\times 10^{-1} \\
\end{array}$ & $\begin{array}{c}T u_{\mathrm{IX}} \\
y\end{array}$ & $T_{\mathrm{W}} / T_{\mathrm{IN}}^{\prime}$ \\
\hline \multicolumn{7}{|c|}{ Siatur } \\
\hline \multirow{3}{*}{$\begin{array}{c}\text { Alts al } \\
\text { (lot) }\end{array}$} & ASRT & $0^{6}$ & 0.913 & $11 . \overline{5 !}$ & (i) & (1) $\overline{7.1}$ \\
\hline & LSKI & $11^{\circ}$ & 0.93 & 1.15 & ii & 11.72 \\
\hline & ASR? & $11^{\circ}$ & 0.932 & 2.11 & i & 0.73 \\
\hline \multicolumn{7}{|c|}{ Rotors } \\
\hline \multirow{4}{*}{$\begin{array}{c}\text { Alts at al. } \\
\text { llitas }\end{array}$} & ARRFi & 5.3 & 1.1 & (1.).1 & 7 & $0 . \overline{1} \mid$ \\
\hline & $A R R L I$ & 5.3 & 1.1 & 1.01 & 1 & $(1 . \overline{1})$ \\
\hline & $A K R I 6$ & 53 & 1.1 & I.111; & 6i & 0.71 \\
\hline & IRRE2 & $.33^{\circ}$ & 11 & $1 . x-1$ & + & 0.73 \\
\hline \multirow{4}{*}{ 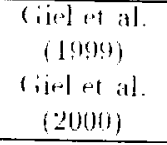 } & (i1KLi & $61^{3}$ & 0.48 & 0.9 & $!$ & 1.07 \\
\hline & ( $\mid \mathrm{KE} 1$ & $64^{\circ}$ & $01,13 x$ & I. & 4 & 1.17 \\
\hline & (i2hes & $61^{\circ}$ & 0.60 & $(1 . \bar{j})$ & $!$ & 1.07 \\
\hline & $(\because 2 \mathrm{~K} E 1$ & $11^{\circ}$ & 11.69 & 0.10 & 9 & 1.07 \\
\hline \multirow{4}{*}{$\begin{array}{c}\text { Blair } \\
\text { (19!1.1) }\end{array}$} & BI)RL1 & $.50^{\circ}$ & 0.11 & 0.12 & ii & 1.07 \\
\hline & BDREA & $50^{\circ}$ & 0.111 & $11 ., \pi$ & 6 & 1.07 \\
\hline & BORF2 & $36^{\circ}$ & $(1.11)$ & 11.2 .1 & di & 1.07 \\
\hline & BOREA & $36^{\circ}$ & $0.111 ;$ & 0.42 & 6 & $1.0 \bar{i}$ \\
\hline \multirow{3}{*}{$\begin{array}{l}\text { 7.hand and } \\
\text { llan (lgyl) }\end{array}$} & ZHREI & $35^{6}$ & 11012 & 0.111 & 14 & 1.07 \\
\hline & ZIIIE:2 & $355^{\circ}$ & $0 .(15)$ & 0.20 & 17 & 1.07 \\
\hline & ZHRE:3 & 350 & $0.0 \overline{6}$ & 11.30 & 17 & 1.07 \\
\hline
\end{tabular}
agreement with the experimental data. Data from Arts et al.[20] for a rotor at a Reynolels number of one million showed little increase in heat transfer on the rear of the pressure surface as the turbulence intensity increased. ('alculations done with the Sinith and linethe model applied even when the flow was turbulent overpredicted the effect of frest ream turbulence for this case. Also, Blair[21] showed that freesteam turbulence effects on liat transfer are diminished for a turbulent boundary layer when the moment un thickness is small. The pressure surface momentum thickness is generally small. Since the Smith and hivethe model does not account for turbulence scale effects. it is expected to only approximately account for turbulence effects. The effect of the Smith and kuethe[19] model on the pretransition lieat transfer will be discussed. The $T u{ }^{\circ}$ product in the model is constant for most of the results presented. If Dunham s[10] correlation had beren used. the $T u t$ product would be less than the upstream value along the forward portion of the pressure surface, where the local velocity is less than the upstream velocity. If the correlation of Steelant and Dick[1 1] were used. the $T u l$ product is greater than the upstream value in this region. Calculations using the Steelant and Dick variation showed leading edge region heat transfer much greater than both the experimental data and calculations done assuming the $T u{ }^{\circ}$ product to be coustant. The reason for the excessively high heat transfer is that the Smith and huethe[19] correlation was developed using the upstream values for $T \prime u$ and $T$. Consequently, when the Steelant and Dick correlation was used, it was restricted to regions where the local velocity was greater than the upstream velocity. Where the velocity was less than the upstream velocity, the assumption was made 
Lable II. Description of model asimmptions.

\begin{tabular}{|c|c|c|c|c|c|c|}
\hline Labxol & Tar. . $1^{+}$ & Lay & $7 \| \mathrm{A} u g$. & $\begin{array}{l}\text { Tu } \\
\text { Var. }\end{array}$ & $\begin{array}{c}\text { Explicit } \\
\text { Rolanumarization }\end{array}$ & $\begin{array}{c}\text { Rolaminarization } \\
\text { Lay }\end{array}$ \\
\hline ('KLI'NTXR & ( $1 \mathrm{~K}$ & $i^{1+}$ & $N_{0}$ & $T u l^{\circ}=C^{\prime}$ & To & - \\
\hline ( 'SLPTANK & ( S & $P^{+}$ & les & $1 u^{\circ}=C^{\circ}$ & No & - \\
\hline ('SNLTANR & 85 & xo & $\operatorname{sen}$ & $T u T^{\circ}=C^{\circ}$ & $\mathrm{No}$ & - \\
\hline ( КIPlı & ( $\mathrm{k}$ & $p^{+}$ & lies & $|u|=c$ & $v_{0}$ & - \\
\hline (KVLTANR & ( $\mathrm{ki}$ & $V_{n}$ & $\operatorname{lin}$ & $T u I^{\circ}=c$ & $\therefore$ & - \\
\hline (KLATAYR & ( "li & $1^{+}$ & lis & $T \| T^{\prime}={ }^{\prime}$ & $x$ & 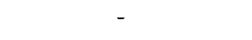 \\
\hline (KLPTARIL & (K & $p^{+}$ & las & $T "{ }^{\prime} I=C^{\prime}$ & lies & No \\
\hline (KI.PTARL & （K & $p^{+}$ & Yins & $T u l^{\circ}=i^{\prime}$ & Sins & Yis \\
\hline CSLPTARNL & 0 & $P^{+}$ & Yis & $T w=C^{\circ}$ & lis & No \\
\hline CKLPSDRNL & $\mathrm{Cl}^{\circ}$ & $P^{+}$ & las & $S D$ & Yis & No \\
\hline$k-\mu$ & - & - & - & - & - & \\
\hline
\end{tabular}

that Tut was equal to the upstream value. Along the suction surface. the product woulel be greater than the upstreant value.

\section{Data Comparisons}

Table I gives some characteristics of the experimental data used for comparisons. The stator data of Arts et al. [22] is included primarily for comparisons of modeling assumptions for frestrean turbulence effects. The rotor geometry cases of Arts et al. [20] are for test cases of four and six percent inlet turbulence. The other rotor test cases are at these turbulence levels or higher. Dring et al.[2:3] gave the turbulence intensity between the stator and rotor of a large scale rotating turbine. Their measurements showed a total unsteadiness of 6.1 and 5.1 percent of the inlet relative velocity for tests with and without a turbulence grid installed in front of the upstream stator. The two test cases of (iiel et al.[24.25] were for tests in a linear cascade with an aspect ratio less than one. The measured flows were highly three-dimensional, and the data showed significant suction surface spanwise heat transfer variatious. Spanwise heat transfer variations on the pressure surface were small. The data are included because the work is concerned with identifying an appropriate approach to predicting heat transfer in favorable pressure gradients. Midspan heat transfer predictions using both two and three dimensional Navier-Stokes analysis wil] be compared with data for these low aspect ratio cases. All rotor data, except for those of Blair[26] at an inlet relative angle. $\beta_{\mathrm{IN}}$ of $36^{\circ}$, are for design incidence. 'The data of Zhang and Han[1] are for very high freestream turbulence levels.

Table 11 summarizes the eleven models used to predict heat transfer. Models beginning with the label $(\mathrm{K}$ use the Crawford and haysi $(K)$ model for $A^{+}$as a function of pressure enadient. Otherwise. the cebeciSimith model is used. The next two letters refer to lagging the near wall damping coefficient. If the letters are VI. there is no lagging. and if they are LA. $A^{t}$ is lagged cxplicitly. For the letters L.P. it is the pressure gradient. $P^{+}$. which is lagged. and $A^{+}$is calculated from the lagged value of $P^{+}$. The next two letlers denotes whether the Suith and huethe augmentation model is used. Only one model. ('KLPNTNR. onits the augmentation. If the letters are SD. the modified Sterlant and Dick[11] variation in turbulence intensity is used both to augnent the turbulence in the Smith and kuethe model. and to determine the start of transition. If the next letter is $X$. there is no explicit relaminarization. For the four models with explicit relaminarization. only one. CKLPTARL, has a lagged relaminarization parameter. $h$. A significant difference between a case with explicit relaminarization, and on where $A^{t}$ becomes very large is that the intermittency $;$. reverts to zero for explicit relaminarization. With $\hat{\imath}=0$. the Smith and liuethe[19] augmentation model is used to augment the turbulent eddy viscosity.

\section{Average surface values.}

Tables III and IV show the average magnitude of the difference between the prediction and data for each of the model assumptions. Results are shown for just the pressure side(Table III), and for the entire blade. (Table IV). The values shown in the tables were calculated by:

$$
D=100 \sum_{n=1}^{n_{\mathrm{EXY}}}\left|h_{\mathrm{C}}-h_{\mathrm{EXP}}\right| / n_{\mathrm{EXP}} \overline{h_{\mathrm{EXP}}}
$$

This estimate of the error is conservative because it does not allow for any positional uncertainty. or effective 


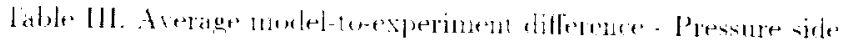

\begin{tabular}{|c|c|c|c|c|c|c|c|c|c|c|c|}
\hline & \multirow{2}{*}{\multicolumn{11}{|c|}{ 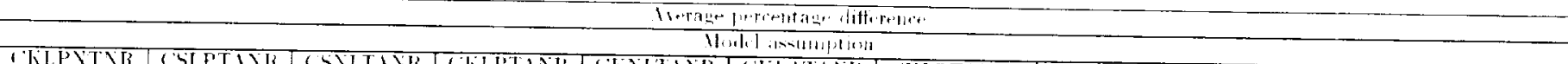 }} \\
\hline Tent atwe & 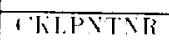 & (ST.FTIVK & 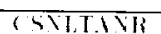 & 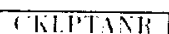 & ("KNITIVR & & & & & & \\
\hline ISRi & $1 \mathrm{IH}$ & 1.1 & $1 !$ & 10 & 1.4 & 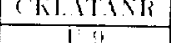 & ('K.PT:TRl. & Y'TIPTARI. & CSIMTIRVI. & (KI.PИR\. & $k-\omega$ \\
\hline $1-k 1$ & 113 & (1) 12 & () & (1) 4 & () 11 & 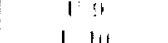 & $1 ! 1$ & $1 \%$ & $1: 4$ & 111 & $12 \pi$ \\
\hline ISII: & 121 & (1) 14 & (1) & () 10 & (1) lii & 10 & $1 \mathrm{Iil}$ & 1111 & 110 & $1 / 1 / i$ & (1) $2 x$ \\
\hline Thkl: & 17 & (1) 27 & (1) 29 & 116 & I ts & 15 & 110 & $1: 1$ & 110 & $12 ! !$ & 112 \\
\hline ARRE & $1 \mid \because$ & (1) $2: 2$ & (1) 21 & () $11 ;$ & & 14 & () $1: i$ & (1) 12 & 114 & (1) $1: 3$ & (1) $2 x$ \\
\hline HRRLG & 111 & $(1)-211$ & (1) 22 & 1119 & $\begin{array}{l}127 \\
1234\end{array}$ & $15 i$ & () 19 & 015 & 114 & () $1: 1$ & 015 \\
\hline MRRK:Z & 111 & (1) 210 & $11 \div 1$ & () $1 ; j$ & $\begin{array}{l}1 \\
0,20 \\
0 \\
2,11\end{array}$ & $1 \mathrm{sin}$ & (1) 2.5 & 0216 & 0 & $0 \geq 1$ & () 1 , \\
\hline 1:1म! & 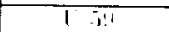 & 137 & $T 3 i$ & 17 & $\frac{1}{3}$ & $151 \mathrm{i}$ & (1) 12 & 0.1 & 12 & (1): & () 11 \\
\hline (iltit! & 1 氷 & $1 \quad 1.7$ & 15 & $1: 1$ & $\begin{array}{ll}1 \\
1\end{array}$ & 15 & 113 & 112 & 113 & 114 & 131 \\
\hline (izlit) & 1261 & (1) $10:$ & $1: 11$ & (1) $1: 2$ & $\begin{array}{ll}1 & \text { in } \\
1 & 29\end{array}$ & 17 & $12 \bar{i}$ & 126 & 121 & 130 & 112 \\
\hline (ZIRF! & $r: 31$ & 110 & 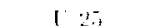 & $1: y-$ & 2.29 & $1: 31$ & 022 & () 2.2 & () $2: 11$ & (1) 2011 & 121 \\
\hline IBLRE: & $T 11$ & (1) 11 & (1) $1 \%$ & 0 & $\frac{1.01}{0.11}$ & $13 i$ & 01,24 & () 21 & () 301 & $(1: 31$ & {$[2: 11$} \\
\hline Horri; & 11. & (1) $1 ! r$ & (1) 20 & (1) & $\begin{array}{lll}0 & 11 \\
0 & 14\end{array}$ & $0 ! 2$ & (1) & () 15 & (1) 13 & (1) 11 & $1:-$ \\
\hline BOOKL: & $1 \%$ & $1: 3$ & $\begin{array}{l}0.201 \\
1.11\end{array}$ & () $1 ! 9$ & 0211 & 017 & () Is & $0: 1$ & $1 \mathrm{IS}$ & () Is & 127 \\
\hline Bont & 1 & 1.3.; & $\begin{array}{l}1 \\
1 \\
1\end{array}$ & 111 & | I & $15 \%$ & 129 & I 20 & $1: 30$ & $1: 31$ & 110 \\
\hline ZHKLI & 1 & & $\frac{1}{1}+11$ & 1.17 & U $\quad: 2$ & 15.3 & 125 & $\mathrm{I}: 30$ & 121 & 124 & $1: 6$ \\
\hline YHRE: & 16 & 13 & 111 & $1: 12$ & 15 & 1.13 & 19 & 17 & 1.1 & 1111 & $1 \| i$ \\
\hline zllki::3 & $1 \quad 1,9$ & 1111 & $\begin{array}{lll}1 & 11 \\
1 & 11\end{array}$ & 192 & 1.23 & $1 \quad \because 2$ & (1) 1 . & (1) $1 \mathrm{ti}$ & 117 & (1) & 1.1 .5 \\
\hline Anratse & 1111 & 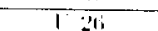 & $\begin{array}{ll}111 \\
122\end{array}$ & 1.19 & 1.1 & 15 & 019 & () $1: 1$ & $11 !$ & (1) 1.1 & 111 \\
\hline Autaz & $3 ! 4$ & $-1: 3$ & $\begin{array}{r}12 . \\
-1.5\end{array}$ & $\begin{array}{l}12 \\
-1 x\end{array}$ & $\begin{array}{l}131 \\
.2-1\end{array}$ & 1.12 & $1 ! 7$ & In & $1 ! !$ & 1201 & 129 \\
\hline
\end{tabular}

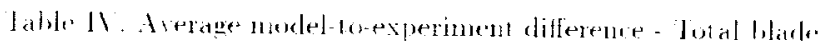

\begin{tabular}{|c|c|c|c|c|c|c|c|c|c|c|c|}
\hline & \multirow{2}{*}{\multicolumn{11}{|c|}{ 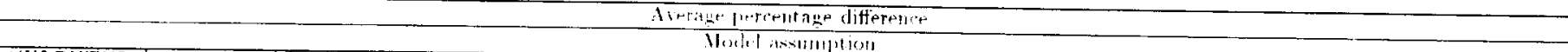 }} \\
\hline Tind intr & TKIPNTIR & & & & " & & & & & & \\
\hline ASाL: & 133 & $\frac{1.9 T .11 R}{11}$ & CSYITKVR & $\frac{\text { CKIPTINR }}{1 !}$ & $\frac{\text { (KNITAVR }}{1.1}$ & CTIATINA & (KI.PTARAL & CRIPTARI. & (SIPTARNL & ('KT.PSDRNI. & $k-\ldots$ \\
\hline ISk1 & $1: 31$ & 11 & 11 & $\begin{array}{ll}1 & 11 \\
1 & 11\end{array}$ & & 113 & 11.1 & 1111 & 111 & 177 & 0.1 \\
\hline $15 R=2$ & 129 & () 11 & () 11 & $\begin{array}{lll}1 & 11 \\
1 & 12\end{array}$ & $\begin{array}{lll}1 & 11 \\
1 & 12\end{array}$ & 111 & 112 & 112 & 111 & 116 & $O+t i$ \\
\hline MRKE & $T 2 !$ & 0.34 & 035 & $\frac{12}{0.9 !}$ & $\frac{112}{1+1}$ & $1+1+$ & 115 & $1: 1 i j$ & I. 15 & $1: 32$ & () 31 \\
\hline ARRE & $11: 3$ & $021 ;$ & (1) 24 & (1) 22 & $\begin{array}{l}1+11 \\
0: 27\end{array}$ & $1+6$ & 027 & (1) 27 & 12 & (1) 25 & (1) init \\
\hline ARRIG & 117 & $0: 1$ & 0.25 & $0 \div 1$ & $\begin{array}{l}0.27 \\
0.2-5\end{array}$ & $13: 4$ & (1) 23 & 0.20 & 0.25 & O 19 & 03.3 \\
\hline IRRF: & () $1:$ & $6 \geq-4$ & (1) 21 & (1) 21 & $\begin{array}{l}0: 27 \\
0: 23\end{array}$ & 13 & (1) $2 \pi$ & 0223 & $0=7$ & 022 & $02 t$ \\
\hline Giki & 199 & 126 & $1 \bar{i}$ & T.:3: & $\frac{0223}{13 i i}$ & $1+j$ & (1) 24 & $(1211$ & (1) 25 & 021 & (1) $:-1$ \\
\hline CitRtl & 1.2 & $13 x$ & I' $3 ! 1$ & 1.11 & $\begin{array}{l}133 \\
112\end{array}$ & $1 \quad 101$ & 121 & 18 & T. 18 & 123 & $1: 24 i$ \\
\hline (12011, & $1: 1$ & 023 & 026 & (1) 21 & {$\left[\begin{array}{ll}1 & 12 \\
1 & 311\end{array}\right.$} & $\begin{array}{l}15 \% \\
153\end{array}$ & 133 & $1: 31$ & 132 & 135 & 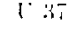 \\
\hline 1:2kr:1 & $r 21$ & (1) 23 & () 25 & (1) 24 & 1 & 124 & (1) 25 & (1) 21 & 127 & 020 & $0: 2$ \\
\hline BMRE! & $134 i$ & $1 \overline{11}$ & 11.5 & 113 & $\begin{array}{l}1 \quad: 3 \\
1\end{array}$ & 132 & 0.25 & 021 & () $24 i$ & ( ) : :? & 1: 15 \\
\hline HI)RFi: & 131 & 117 & 111 & $1: 11$ & & 1.4 & 113 & 11.3 & 1.13 & 113 & $12 \overline{1}$ \\
\hline BORL1:? & 111 & 124 & (: :30 & 12 & $\begin{array}{ll}1 & 11 i \\
1 & 33\end{array}$ & 116 & 113 & $1: 11$ & 111 & I $16 i$ & 110 \\
\hline BORIA & $1+2$ & [ 24 & I 28 & $1 \cdot 29$ & $\begin{array}{l}133 \\
134\end{array}$ & 110 & 121 & 120 & 121 & 122 & $1: 37$ \\
\hline ZHRHI & $1 !$ & 126 & 125 & 126 & $\frac{1}{124}$ & 138 & 19 & I: 21 & $r 20$ & 120 & $r 3 x$ \\
\hline ZHKL: & 1.32 & $1: 31$ & $1-30$ & 131 & $\begin{array}{l}127 \\
1.21\end{array}$ & 132 & 111 & $1: 13$ & 114 & $11 \%$ & 136 \\
\hline z1161.3 & 1 in & 127 & (1) 24 & {$[: 301$} & 131 & {$[.11]$} & $01: 4$ & $01 \bar{i}$ & 019 & 01.1 & 131 \\
\hline Amray. & 134 & 1233 & 121 & $12 \%$ & $-\frac{1}{1}: 31$ & 131 & () 201 & 017 & 020 & 11.5 & $1: 2 \pi$ \\
\hline Arotane & .31 & $\therefore$ & $-\bar{i}$ & $x^{-x}$ & $\begin{array}{l}127 \\
-11\end{array}$ & 132 & 120 & 119 & 121 & 121 & 133 \\
\hline
\end{tabular}

width of the measurements. In regions of high gradients the actual error would be less if the measurement locations were moved within their uncertainty limits.

For Table III. $\overline{h \text { ExP }}$ is the average experiment al heat transfer coefficient for just the pressure surface. For the results in Table IV. this value is the average for the entireblade. The letters $I^{\circ}$ and $O$ in these tables indicate whether the average predicted heal transfer was either less.( $\left.\mathrm{C}^{\top}\right)$, or greater.(O), than the experimental value. Crenerally, the magnitude of the average differrnce' was less than that shown in Tables III and IV. Only if the model either underpredicted or overpredicted the heat transfer at every measurement location would the average difference and the value of $D$ be the same. Two overall averages are shown for each model. The one preceeded by a $\mathrm{I}$ or $\mathrm{O}$ is the average absolute difference, $D$, of the eighteen cases. The letter is $U$ if more than half the cases were underpredicted. and $O$ if more than half are overpredicted. The other one is the average of all data points for all eighteen cases. without taking the absolute value. A negative value means that the analysis underpredicted the heat transfer.

Comparing results using the ('KLPNTNR model with those using the CKLPTANR model shows the effect of the Snith and Kuethe turbulent augmentation model. On the pressure side, not augmenting the eddy viscosity resulted in an underprediction for all cases. The average absolute difference was 40\%. The average 
undeprediction was nearly as large, $39 \%$. Seren of the eighteen pressure surface cases were overpredicted using the (KLPTANR moded. and overall the molerprediction was 18\%. (onsilering the entire surface. Table IV shows that the ('KLPNTXR model gives an overperdiction for only one of the eighteen cases. Again. the absolute difference is latge. $31 \%$ and 1 he moleppediction is nealy as grea1. 31\%. The (KLPTANR model gives an overprediction for six casss. and the muderpediction is $18 \%$. This shows the desirability of including a moled for the effect of freest ream turbulence on edely viscosity. and the reasomablentse of the model rbosen.

[able. Ill show lhat the (raw ford and liass model with a lag for $P^{+}$, (KLPTANR, has an average alisolute difference of $27 \%$. Without a lag for $P^{+}$. ( $\mathrm{K} \times \mathrm{L}-$ TANR. the average absolute difference increasen to $34 \%$. As figure 1 shows the effect of a lagging $P^{+}$is smaller for the Celpeci-smith model. Both the CSLP. TANR and CSNLTANR results show similar average absolute differences. For both the pressure surface. and the entire blacke the (KLPTAXR and 'SIPTAXR models have similar. but not identical. absolute differences. The C'KlPTAXR model is more sensitive to $p+$ variation. and underpredicts the heat transfer to a greater extent. Based on the comparisons between the ('SLPTANR and CKLPTAXR model results, there is little reason to believe that a constant value for $\mathrm{A}^{+}$ would not give satisfactory heat transfer predictions. However since a value for $i^{+}$as a function of $P_{E F F}^{+}$ agres better with data than $A^{+}$as a function of $P^{+}$. using a non-constant value for $A^{+}$is appropriate.

$A$ constant $A^{+}$is not affected by whether $P^{+}$is lagged or not. The CKLATANR model, where $A^{+}$is lagged, but the equilibrium value of $f^{+}$is calculated from the local value of $P^{+}$lias a greater absolute difference than the (KLPTANR model. indicating that $A^{+}$ should not be lagged directly.

The CKLPTARNL and CKLPTARL model results show that forcing relaminarization explicitly improves the agreement with data. Comparing these model results with the CKLPTANR results show that explicit relaminarization improves the average agreement with data. The improvement in the average absolute difference is nearly $10 \%$ for the pressure side, and over $3 \%$ for the total blade. The improvement in the average difference is greater, being nearly $17 \%$ for the pressure side, and $7 \%$ for the total blade. These results indicate that explicit relaminarization is appropriate. With explicit relaminarization freestream turbulence increases heat transfer whenever the boundary layer is not fully turbulent. Whether $K$ or $K_{\text {EFF }}$ should be used as a criteria for relaminarization is addressed subsequently.
The differences in prenlicted heat transfer between the ('KLPTARNL and ('SLPTARNL models are less than the differences botween the ('kLPTAXk and CSLPTANR models. The neas wall damping modeds are employed only when the the flow is not laminar. For the assmuption of relaminarization. there is linte evidence 10 prefer one form of mat wall damping over the other.

The modified steelant and Dick model for the local turbulence intensity did not improwe heat transfer predictions compared with the ('KLPTARNI model. The model predicted the variation in turbulence intemsity for the data of Zhang and Han[1]. But, it resulted in decreased angmentation in the Simith and kuethe model for the rear portion of the pressure surface.

It will be shown that when the $k- \pm$ model molerpredicted heat transfer. it was often due to not accomting for fresstream turbulence effects prior to transition. When heat transfer was overpedicted, it was often due to transitjon occurring sooner than was seen in the data.

\section{Blade surface comparisons.}

Nex1. heat transfer comparisons will be shown for each of the eighteen cases to illustrate the local heat transfer for the different model assumptions. Eleren of the cases show the ('KLPTARNL model results. For clarity, each comparison with data shows results for only a few model assmuptions.

Stator vane comparisons. Figure 3 shows comparisons with the stator data of Arts et al.[22]. The lowest Reynolds number results show that augmenting laminar viscosity to account for freestream turbulence improves the agreement with data. both in the leading edge region and all along the pressure surface. The $k-2$ model shows too early transition on both pressure and suction surfaces. It also shows no augmentation of laminar heat transfer due to high freestream turbulence.

At the intermediate Reynolds number both ('rawford and hays near wall damping models agree well with the data. The Cebeci-Smith model gives too high heat transfer towards the rear of the pressure surface. The explicit relaminarization model. CKLPTARNL. gives lower heat transfer for the rear of the pressure surface, indicating that a relaminarization criteria greater than $3 \times 10^{-t}$ is appropriate. A1 the highest Reynolds number. the pressure surface heat transfer is significantly underpredicted by the CKLPTARNL model, and even more so by the ChLPSDRNL model. The data show no evidence of relaminarization. Because of favorahle 

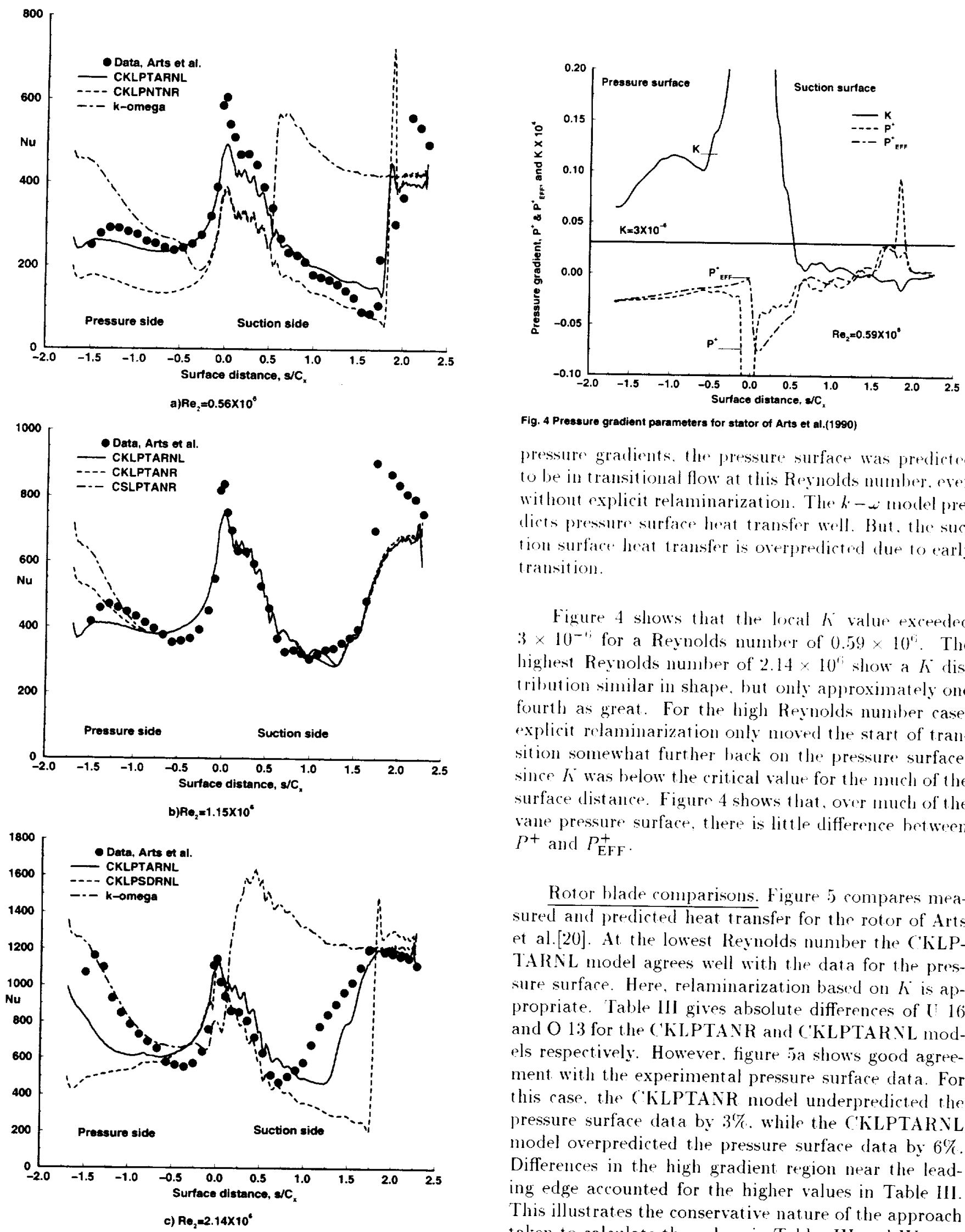

Fig. 3 Comparison with the data of Arts et al.(1990) 

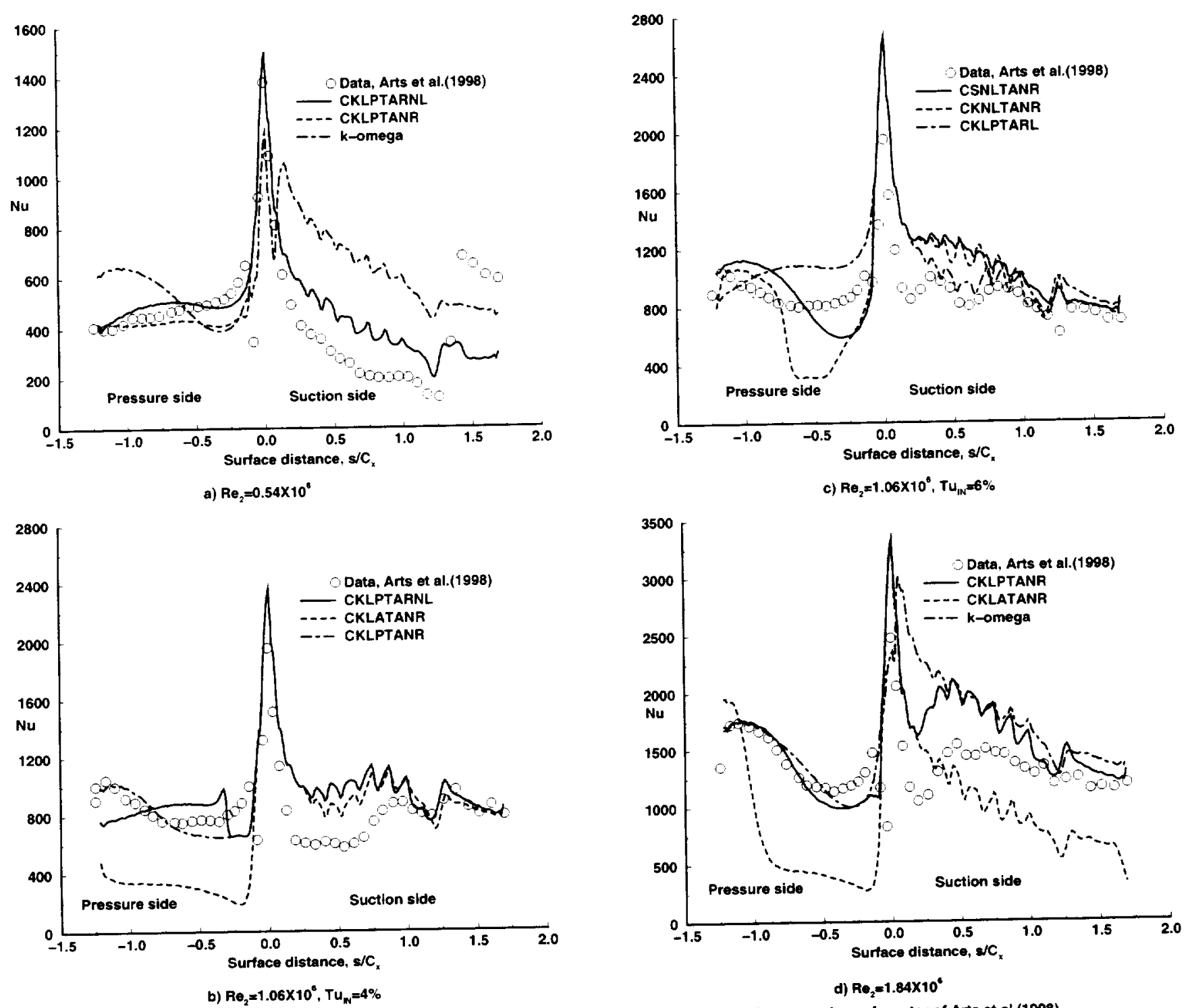

The CKLPTARNL and CKLPTARL results in Table III shows that lagging $K$ has little effect on the pressure surface prediction for the low Revnolds number case. Both the $k-\downarrow$ and CKLPNTNR model typically give leading edge Frossling numbers near one. With high freestream turbulence, data show Frossling numbers typically forty to fifty percent greater. Suction surface transition occurs close to the trailing edge because of the favorable: pressure gradients. The Simith and Kuethe frestream turbulence model overpredicts laminar region suction surface heat transfer.

Figure jh shows good agreement with the pressure surface data for the CKLPTANR model. The relaninarization model, CKLATARNL. shows a flat pressure surface heat trausfer distribution, and underpredicts 
Without retaminarization. the (ebeci-Smith near wall

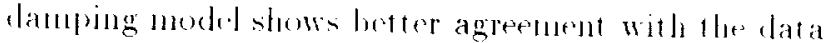

The lightest Reyolda number comparisoms show that the (KLPTANR and $k-\infty$ models give good agreetIllent with data for the pressure surface. On the suction surface botle nocelets overpredict the heat transfer. For the (KLPTANR moded this is der to overpredictite the effect of freestrean turbulence prior to transition. rigures 15l, and lid show that the (KLATANR model gives poor agreement with pressure surface data. This occurred becaluse the vilue of $A_{\mathrm{EFF}}^{+}$was much greater than the local value of $t^{+}$.

Figures is shows that the analysis overperellets freest realu turbulence effects prior to transition for the suction surface. This is a conserpuence of how the Sinith and kuethe[19] toodel was implentented. The turbulent redely visconity was angmented for a large muntber of griel lines extending outward from the surface. Boyle and Simon[s] implenented the Sunth and kuethe mondel lifferently, and achieved better agremente with data. They added the angmentation only in the inner region of the bondary layer. However. the inner region was determined from calculations for a turbulemt bomdary laver. Also. the location in terms of $y^{+}$. varied depending on the type of turbulence model used. This indicates that the Sulth and kuethe augmentation should be applied only over a range of $y^{+}$values. Infortunately, the appropriate $y^{+}$value is not known.

ligure tia slows 1 le variation in $P^{+}$and $P_{\mathrm{EFF}}^{+}$along the blade surface for the lowest and highest Reynolds nunthers. At the highest Reynolds number. there is litte difference between the lagged and local values of $P^{+}$. At the lowest Reynolds numbers the differences are more noticeable, and are caused by the high value of $\mathrm{P}^{+}$near stagnation. At the lowest Reynolds number the maximum value of $s^{+}$on the pressure side is only about ten times the value of $C_{\mathrm{LAg}}$. At the highest Reynolds number. the maximum value for $s^{t}$ is over thirty times the value of ${ }^{\mathrm{LAC}}$.

(omparing figures 6 a and $6 \mathrm{~b}$ shows that the ratio of the maximum-to-average value of $K$ is much greater than the same ratio for $P^{+}$. For clarity, the ratio of $K$ to the value used to set relaminarization. $3 \times 10^{-1 i}$. is shown. and negative $K$ values were onitted. In the relaminarization model. when the ratio exceeds one. relaminarization occurs. This illustrates why lagging $h$ to determine $\kappa_{\mathrm{EFF}}$ is not appropriate. In the stagnation region the freestream velocity approaches zero, and the local value of $K$ becomes very large. At the lower
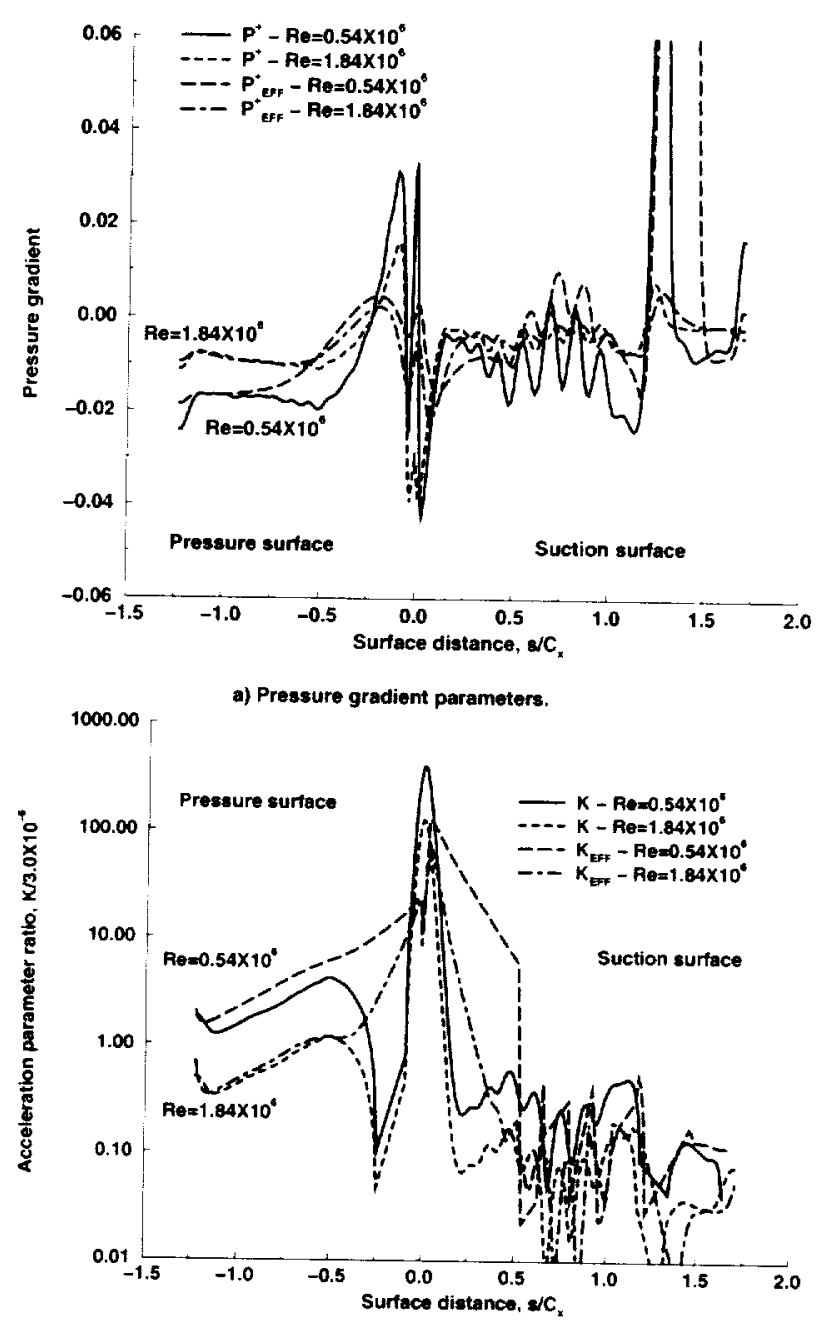

b) Acceleration parameters.

Fig. 6 Presure gradient parameters for rotor of Arts ot al.(1997).

Reynolds number. the high $K$ value near the stagnation point causes $h_{\text {EFF }}$ to exceed $h$ all along the blade pressure surface. The is because the lag coefficient. (CAG. is about ten percent of the trailing edge $s^{+}$value. At the higher Reynolds number the local $s^{+}$value is nearly four times greater, and $K_{E F F}$ approaches $k$.

The suction surface results in figure 6 illustrate that, if a lag equation is implemented. it should be calculated from a slightly smoothed parameter value. Too much smoothing will introduce additional lagging. In Navier-Stokes. as opposed to boundary layer, calculations large streanwise steps are used. For a hundred surface points the distance between grid lines. $\Delta s^{+}$is on the order of ten percent of the lag constant. This can int roduce instabilities in calculating the lagged value if the local value is oscillating. 

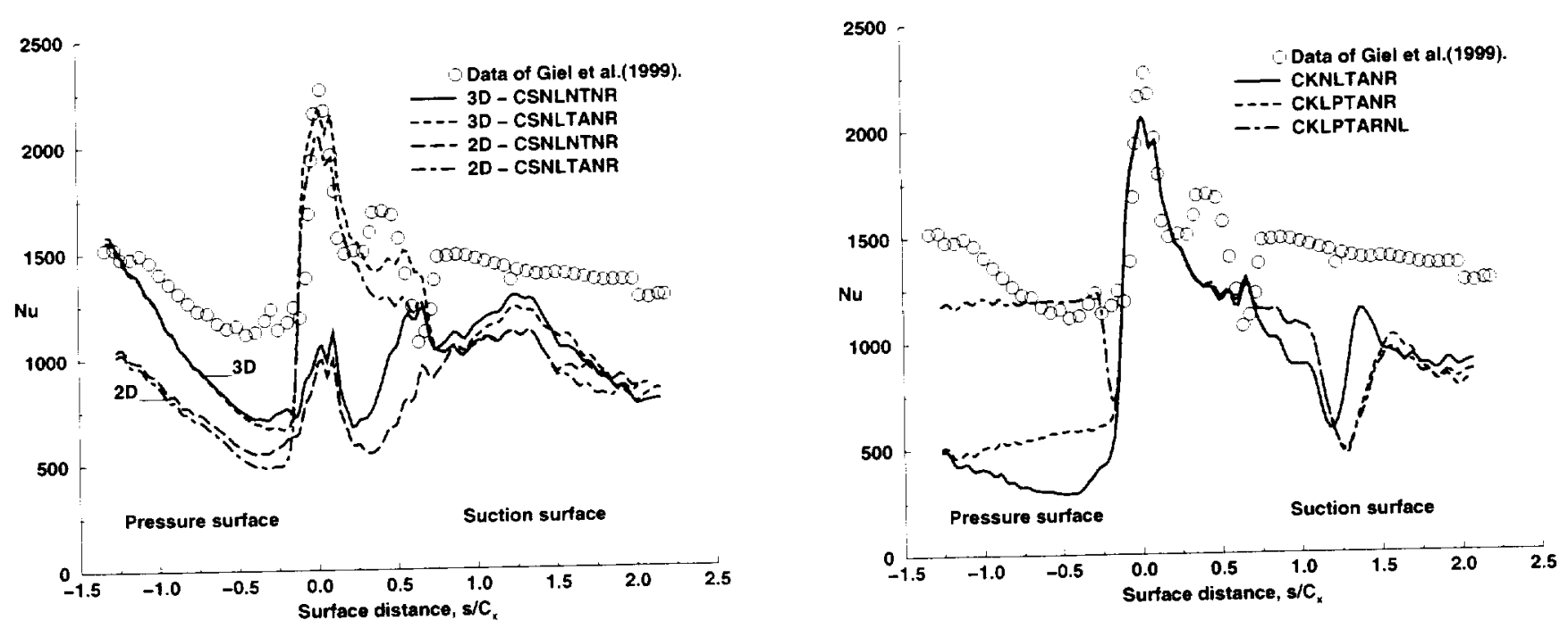

a) Case G1RE5 $-\mathrm{Ae}_{2}=0.9 \times 10^{\circ}$

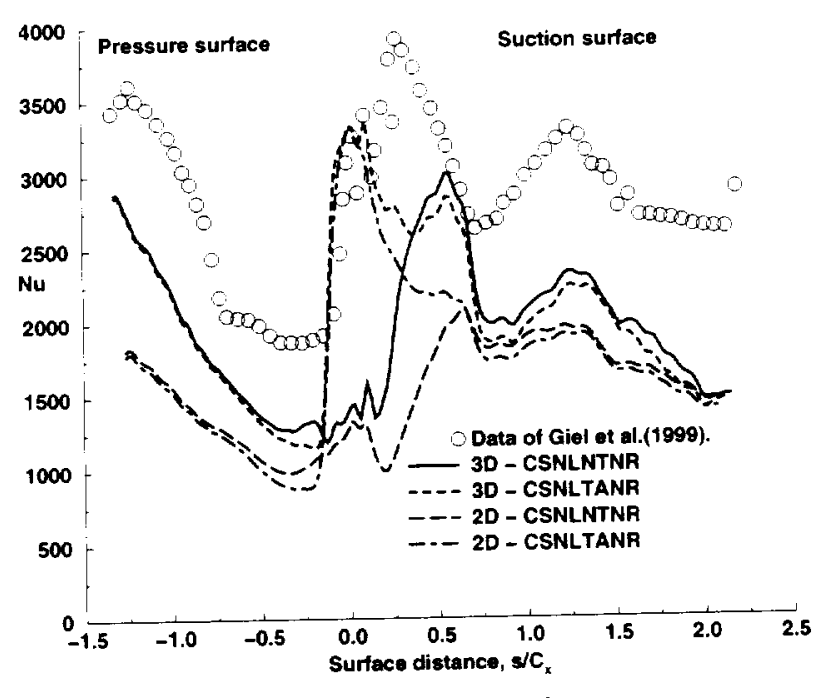

b) Case G1RE1 - $R \theta_{2}=1.8 \times 10^{\circ}$

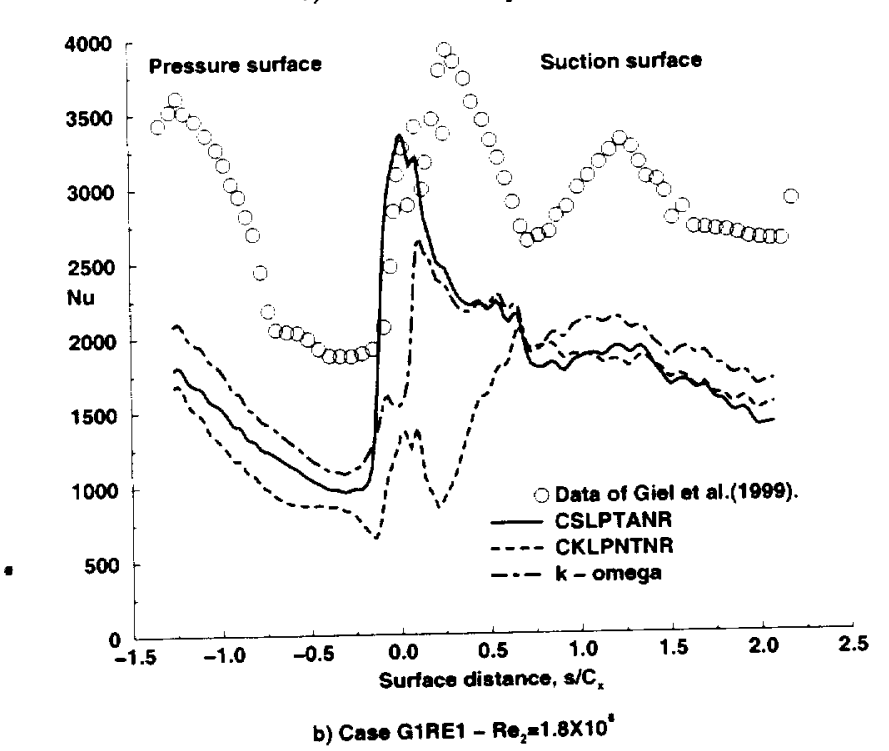

Fig. 7 - Comparison of $2 \mathrm{D}$ and 30 midspan prodictions.

Fig. 8 Two dimensional heat transfer predictions and data.

Both two-dimensional(2D) and threedimensional(3D) flow analyses were done for the low aspect ratio test cases of Giel et al. [24,25]. Figure $i$ compares midspan heat transfer from the two NavierStokes analyses. The 3D analysis was done with and without augmentation for freestream turbulence. The turbulent eddy viscosity was calculated using the model of Chima et al.[16]. The 3D analysis was described by Chima and Yokota[13] and Chima[2T]. The 3D predictions with augmentation for freestream turbulence were for the CSNLTANR turbulence model. Calculations done without freestream turbulence augmentation are labeled CSNLNTNR. The experimental data of Giel et al.[24] showed large spanwise suction surface heat transfer variations. and these variations were also seen in the

$3 \mathrm{D}$ predictions. However, at midspan the only significant difference between the $2 \mathrm{D}$ and $3 \mathrm{D}$ suction surface heat transfer predictions is that the 3D prediction shows an earlier transition location. The difference between the 2D and 3D pressure surface heat transfer predictions was unexpected. Data and the 3D prediction showed little spanwise variation. However beyond the leading edge region the $2 \mathrm{D}$ predictions are lower than the $3 \mathrm{D}$ prediction. For the pressure surface as a whole. the $2 \mathrm{D}$ predictions are $15 \%$ lower than the $3 \mathrm{D}$ predictions. Accounting for three dimensional effects would increase the predicted heat transfer for these two cases. The CSNLTANR model would change from I 36 and U 45) to $\mathrm{I} 21$ and $\mathrm{C} 29 \mathrm{using}$ the 3D midspan predictions. 


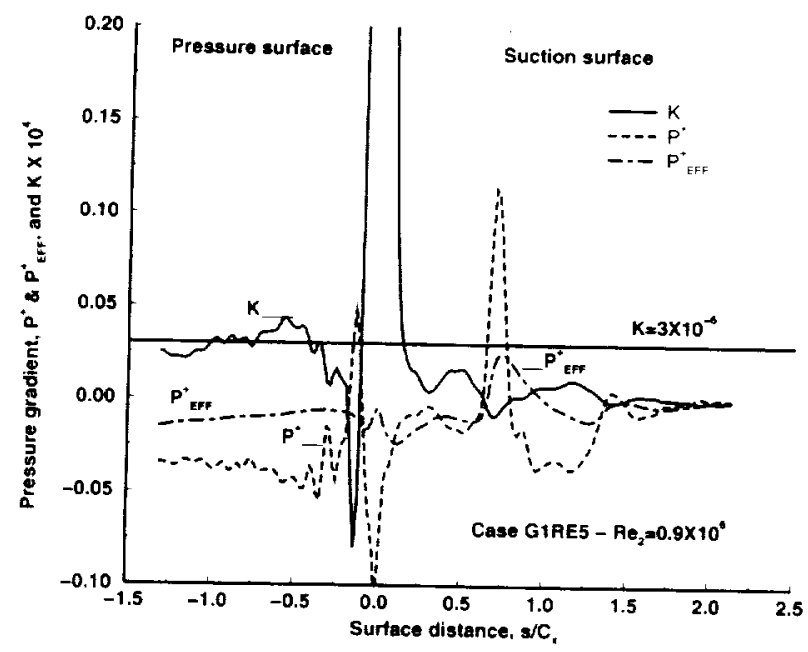

Fig. 9 Pressure gradient parameters for rotor of Giel et al.(1999).

ligure s shows 2 D heat transfip comparisons for the rotor tested by (iiel et al. [2-1]. Fur the lower Reynolds mumlier comparison only the (KLPTARNL model approaches the pressure surface heat transfer. In the ('KLPTANR model relaminarization does not occur. Becalse of strong favorable pressure gradients. $\mathrm{A}^{+}$remains very large, and the pressure surface heat transfer remains low. In the (KLPTARN nodel relaminarization eccurs. With relaninarization the Smith and kuethe model is activated. The suction surface is underpredicted. hut as figure $i$ a shows, the Cebeci-Snith models are cloner to the dat a. The noticeable differences betwern the CKLPTANR and CKNLTANR model results are due to lagging the pressure gradient. The ('KLPNTXR model results in figure st) show that neglecting freestream turbulence effects gives heat transfer much lower than the data. Figure sh shows that the cSIPTANR model results are closer to the pressure surface data. than are the CKLPTANR model results. The (SLPTANR model predicts lower pressure surface $1^{+}$values.

Figure!) shows the acceleration and pressure graditht parameters for the low Reynolds number, GIRE5. case. The acceleration parameter. $k$, exceeds $3 \times 10^{-6}$ on the pressure surface. But the data in figure 8 a does not show a flat pressure surface heat transfer distrihution, characteristic of relaminarized flow. This again implies a relaminarization criteria greater than $3 \times 10^{-5}$. Over much of the pressure surface $P_{\mathrm{EFF}}^{+}$is only about half of the value of the local pressure gradient. $P^{+}$.

Figures 10-12 show comparisons with data for tests done in the same facility as for comparisons shown in figures $i-9$, but for a different rotor geometry. The Reynolds numbers were also different. The comparison of $2 \mathrm{D}$ and $3 \mathrm{D}$ midspan heat transfer shown in figure
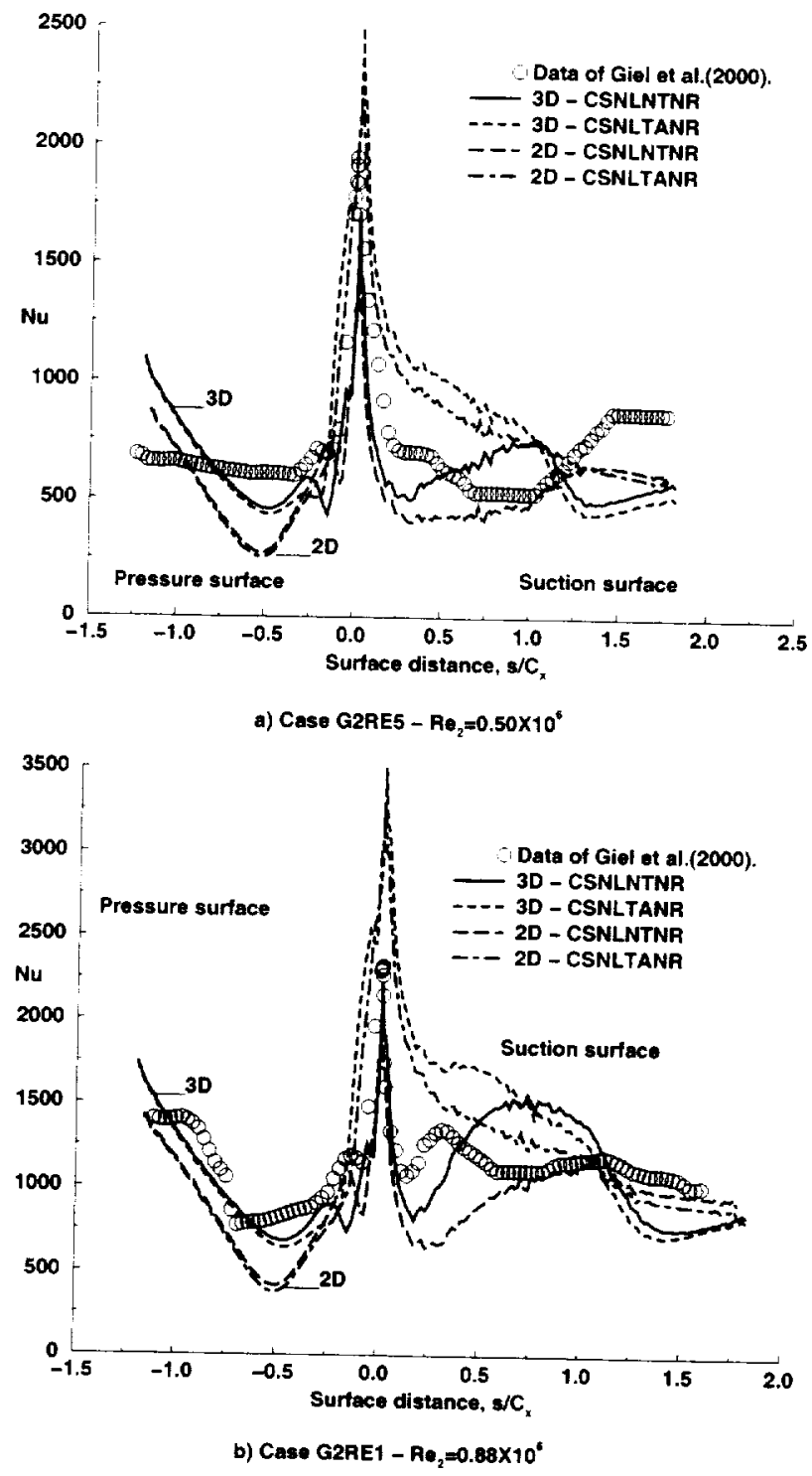

Fig. 10 Comparison of $2 \mathrm{D}$ and 3D midspan heat Iransfer.

10 is similar to that shown in figure 7 . On the suction surface the model without augmentation. CSNLNTNR. shows an earlier transition start for 3D flow than it does for $2 \mathrm{D}$ flow. The results in Table III for the CSNLTANR model would change from $\mathrm{I} 20$ and $\mathrm{I} 25$ to $(0) 20$ and C 19 if the $2 \mathrm{D}$ predictions were replaced by the $3 \mathrm{D}$ predictions. The change in sign from $\mathrm{C}^{-} 20$ to $\mathrm{O} 20$ is misleading. The average pressure surface heat transfer goes from a $10 \%$ underprediction to a $6 \%$ overprediction. These two cases also have $2 \mathrm{D}$ pressure surface $15 \%$ lower than the 3D predictions for the same turbnlence model. Fourteen of the eighteen test cases were for blades with a greater asject ratio. The differences between $2 \mathrm{D}$ and $3 \mathrm{D}$ predictions would be less than for these two cases. 

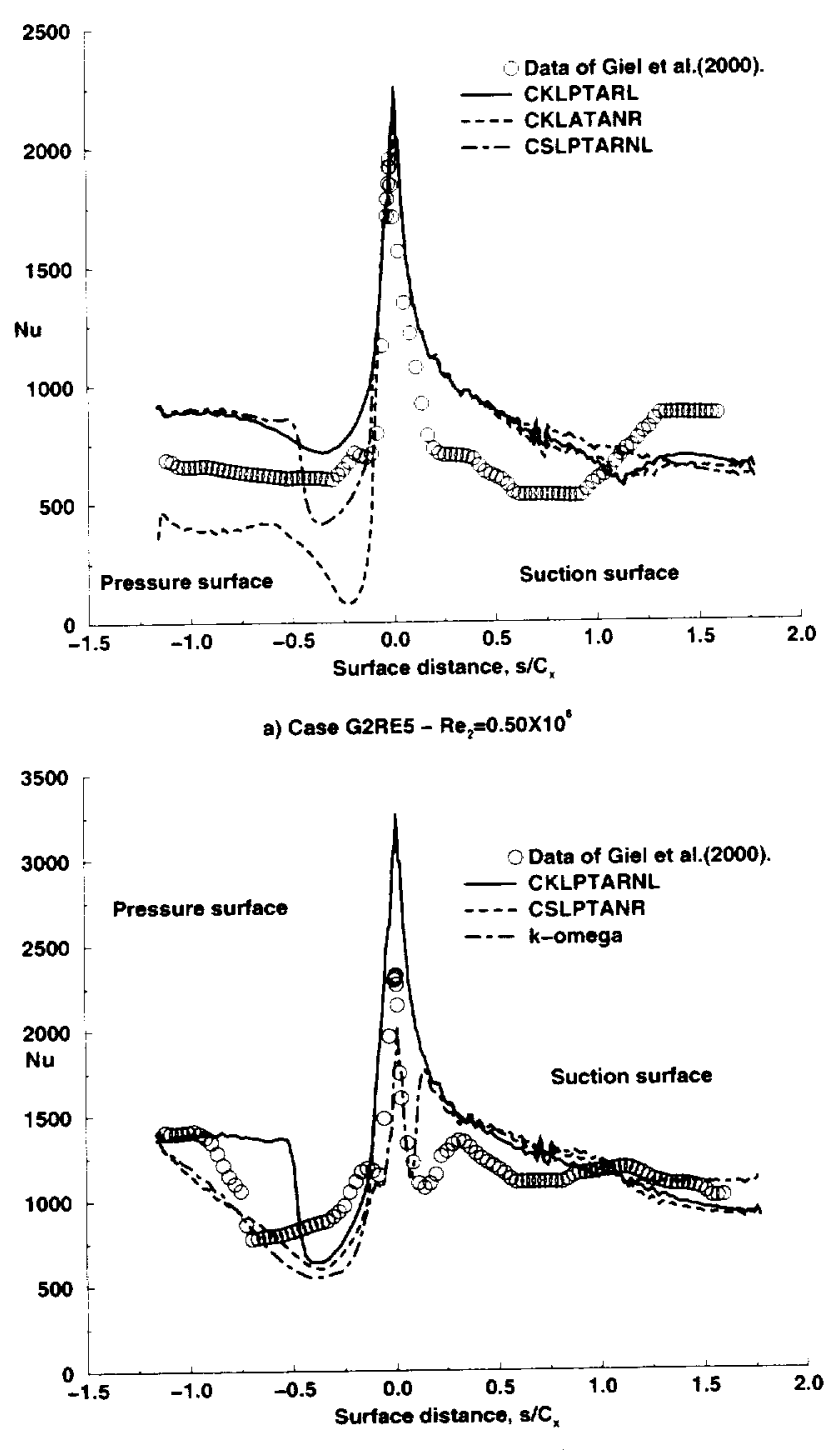

b) Case G2RE1 - $\mathrm{Re}_{2}=0.88 \times 10^{\circ}$

Fig. 11 Comparison of heat transfor model prodictions with data.

Accounting for 3D predictions for the four cases of Giel et al. $[24,25]$ would change the overall pressure side CSNLTANR model averages from $42 \pi \%$ and $-1.5 \%$ to I $24 \%$ and $-12 \%$. Additional calculations for these four cases using relaminarization models showed differences between $2 \mathrm{D}$ and $3 \mathrm{D}$ midspan heat transfer about half that for the non-relaminarizing models.

Figure 11a shows that the ChLATANR model. which lags $\mathrm{A}^{+}$directly, underpredicts the pressure surface heat transfer. This is consistent with the comparisons shown in figure 5h. Table III shows that the Crawford and kays model and the Cebeci-Smith model go from underpredicting the heat transfer to overpredicting it when a lag equation is used for $P^{+}$for this test case. The ('KLPTANR model is in reasonable

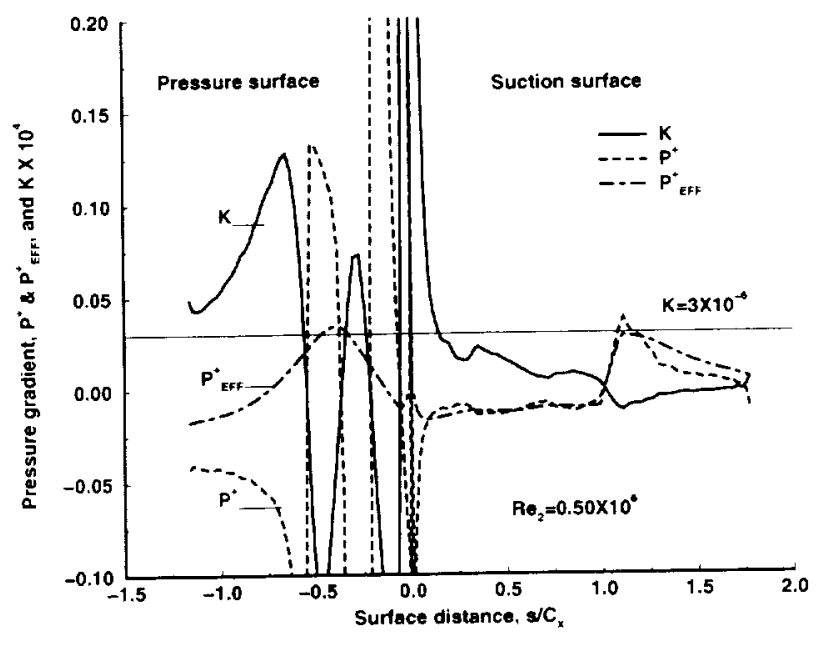

Fig. 12 Pressure gradient parameters for rotor G2RE5.

agrement with the stagnation region heat transfer, hut significantly overpredicts the suction surface luat transfor prior to transition. The (SLPTARXL model results are similar to those for the (KLPTARL model. With 110 relaminarization lag. heat transfer is underpredicted on the forward part of the pressure surfact.

For the higher Reynolds number case shown in figure 111, the $h-\omega$ and CSLPTANR models agree well with the presure surface data. The $k-\infty$ and ('KLPTANR model result are very close over most of the suction surface, and the flow is predicted to be turbulent. The heat transfer overprediction after transition is not due to overestimating freestream turbulence effects. It is possibly due to three-dimensional effects.

Figure 12 shows large variations in pressure surface pressure gradient and acceleration parameters at the lower Reynolds number of $0.50 \times 10^{\circ}$. The pressure surface flow accelerates. decelerates. and then reaccelerates. This accounts for the large difference between $P^{+}$and $P_{\mathrm{EFF}}^{+}$, even close to the trailing edge.

Figures 13a and 13b show comparisons with the data of Blair [26] for design incidence. For theses case lagging $P^{+}$shows little effect. The CKNLTANR model agrees well with the data in figure 13a. and the (KLPTANR model agrees reasonably well with the data in figure 13b. Figure 13b shows almost the same beat transfer rates when $K$ is lagged and when it is not. The $k-w$ model does not agree well with the pressure surface data. but does agree well for the suction surface.

Figures $13 \mathrm{c}$ and $13 \mathrm{~d}$ show that off-design incidence cases have poorer agreement than design incidence cases. There is good agreement with the suction surface data. The relaminarizing models agree well with lata for the aft half of the pressure surface. but all models underpredict heat transfer for the forward portion. 

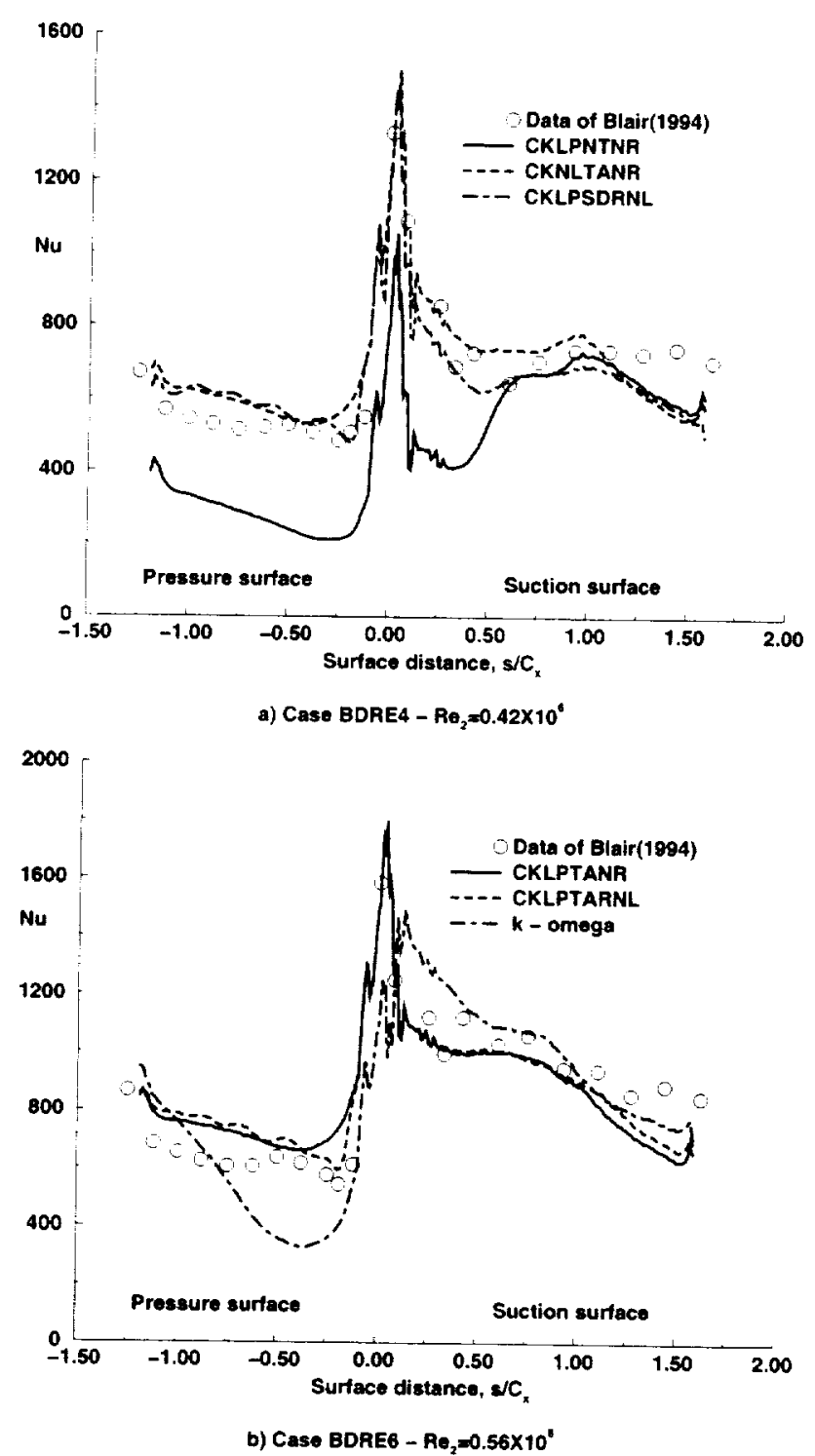

The pressure gradient parameters in figure 14 are for a Reymolds mumber lower than in the previous cases. The design incidence curves in figure 14 a and those in figure 12 have similar shapes. $P^{+}$and $P_{\mathrm{EFF}}^{+}$differ substantially, even near the pressure surface trailing edge. At off-design incidence the flows accelerate. decelerate, and finally accelerate along the pressure surface. The effective pressure gradient, $P_{\mathrm{EFF}}^{+}$, on the pressure surface is so dependent on what happens near the leading edge, that it is positive and off the scale in figure $14 \mathrm{~b}$. This behavior, resulting from the low Reynolds number, and the associated low $s^{+}$values. makes any use of a lag equation problematic.

Figure 15 shows comparisons with the data for the three low Reyuolds number cases of Zhang and Han[1] The cases have high inlet turbulence. For the lowest 


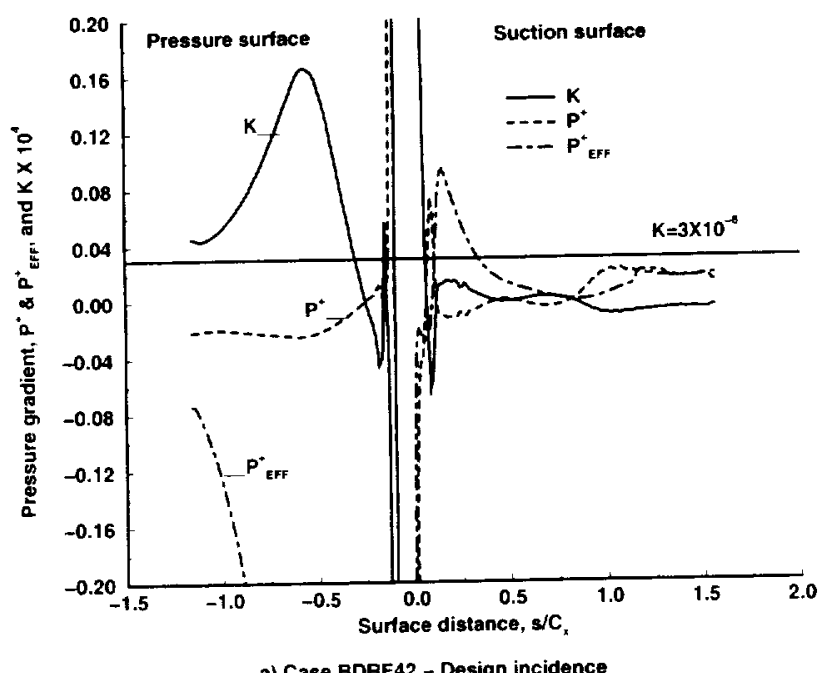

a) Case BDRE42 - Design incidence

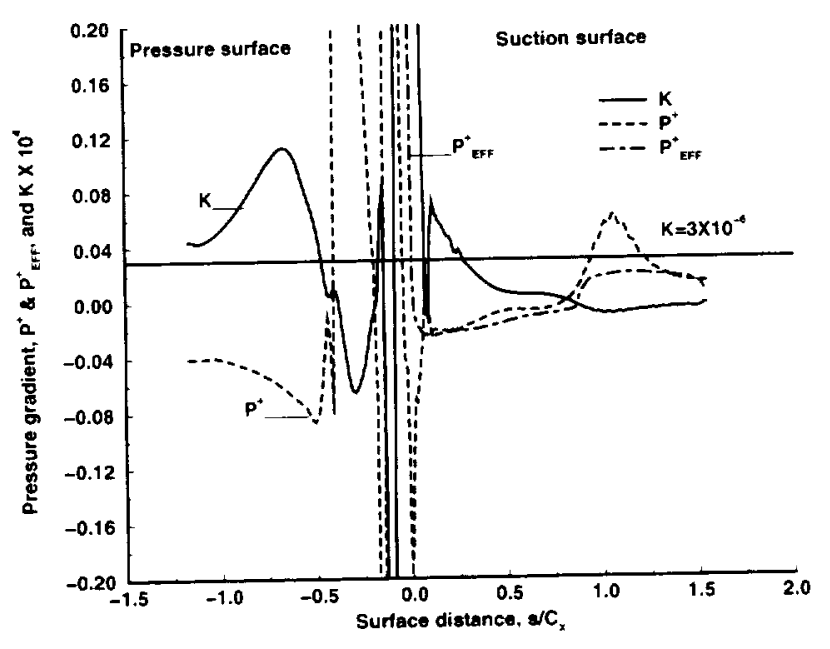

b) Case BORE2 - Otf design incidence.

Fig. 14 Prossure gradient parameters for rotor of Blair(1994) at Re $=0.42 \times 10^{6}$

The non-relaminarizing models have very low pressure surface lieat transfer after the leading edge. The apparent transition seen in the suction surface data is not seen in the predictions.

Figure 15c, for the highest Reynolds number, again shows that a relaminarization model best predicts the shape of the pressure surface heat transfer distribution. Without relaminarization, and therefore, without augment ation due to freestrean turbulence after transition, the heat transfer is low due to strong near wall damping at this still relatively low Reynolds number. On the pressure surface, the $b-\dot{m}$ model shows very low heat transfer just after the leading edge region. This model also underpredicts the leading edge region heat transfer. All three model predict similar suction surface heat transfer away from the leading edge region.

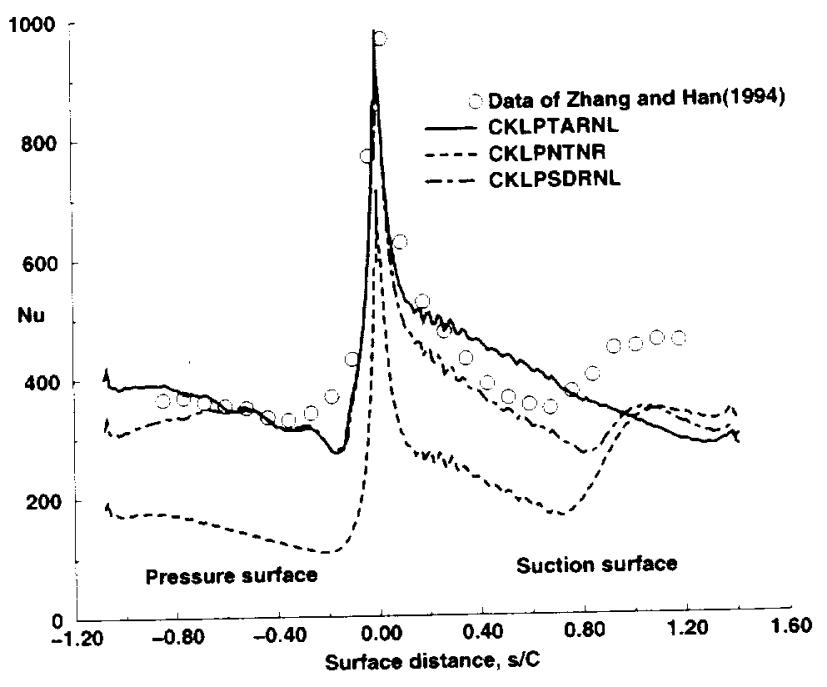

a) Case ZHRE1 $-R e_{2}=0.10 \times 10^{6}$

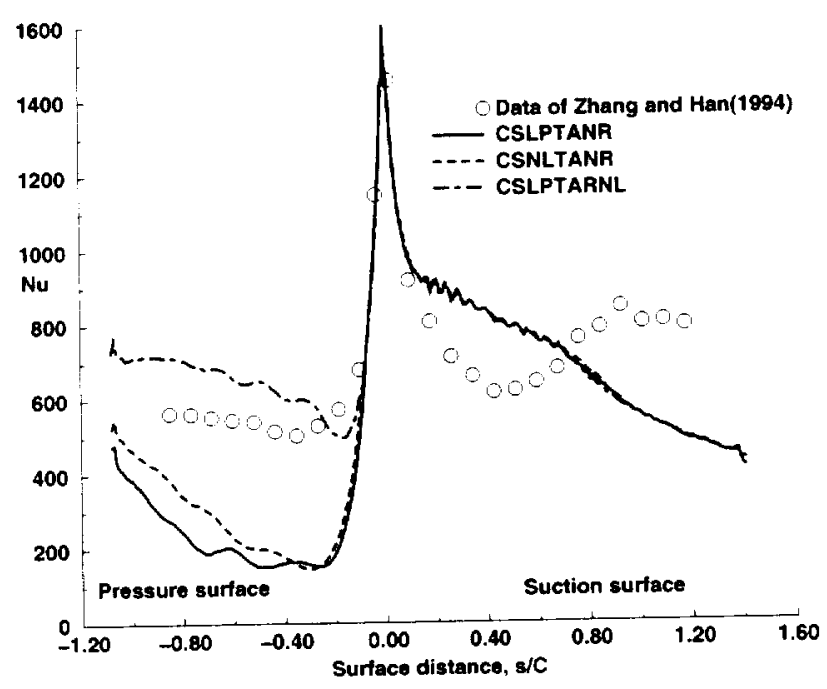

b) Case ZHRE2 - Re, $=0.20 \times 10^{\circ}$

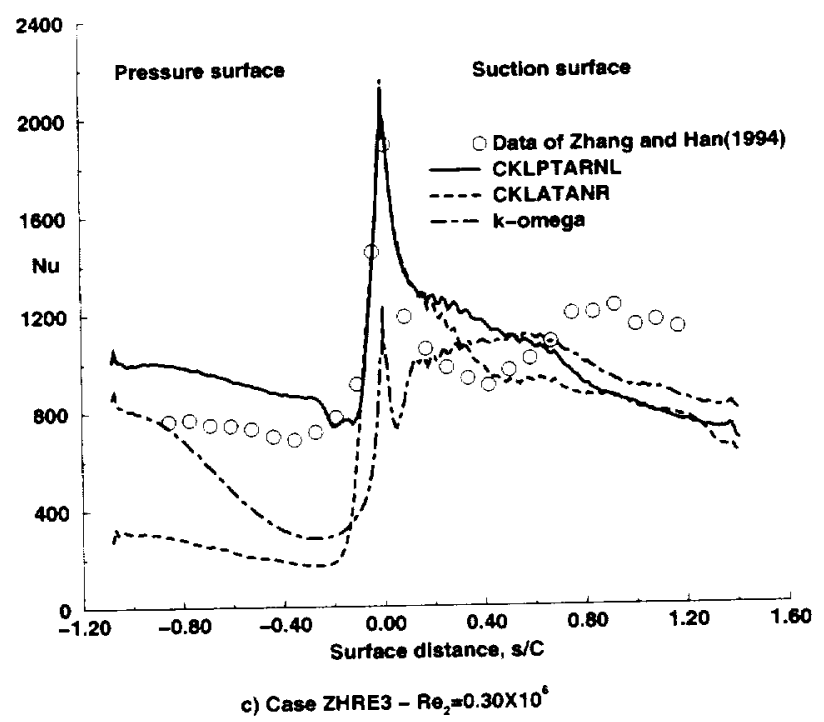

Fig. 15 Heat transfer comparisons for rotor of Zhang and Han. 


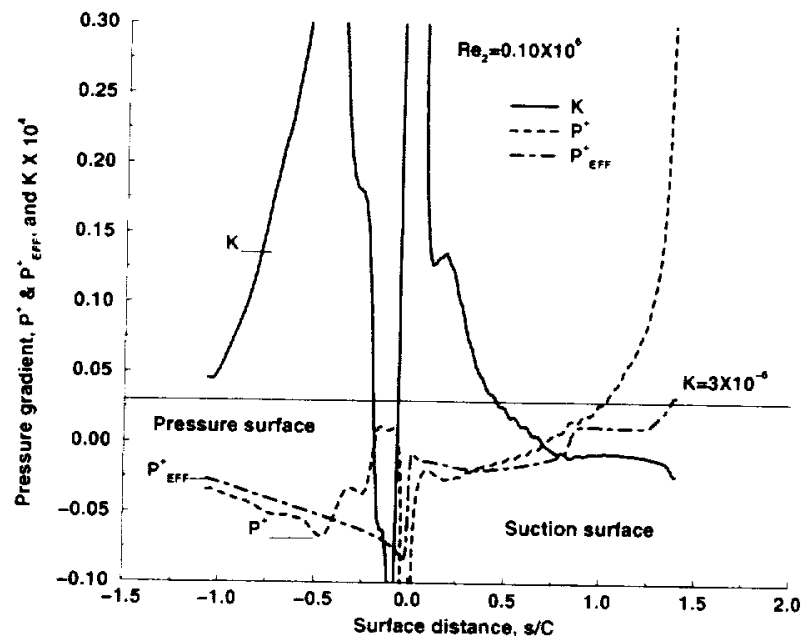

Fig. 16 Pressure gradient parameters for rotor of Zhang and Han(1994).

Figure 16 shows the acceleration parameters for the rotor of Zhang and Han[l] at the lowest Reymolds number. The values of $K$ are very large. Even if divided by thres to account for the highest Reynolds number. relaminarization is indicatel. Orer much of the pressure surface there is litte difference hetween the local and lagged presinter eradient values.

\section{CONCLUSIONS and RECOMMENDATIONS}

Based on the results for the entire blade a variable near wall damping coefficient is appropriate. The ('rawford and Kavs[5] damping coefficient produces a laminar like boundary layer at a lower favorable pressure gradient than does the Cebeci-Smith damping coefficient. The ('rawford and hays model was more likely to moderpredict the heat transfer. The results of this work indicate that a constant value of $A^{+}=26$ would werpredict the heat transfer level for many cases.

Explicit relaminarization improved agreement with data, particularly at low Reynolds numbers. The improvement occurred because when relaminarization occurred, the Simith and Kuethe [19] turbulence nodel was used to increase eddy viscosity. The average heat transfer increased when relaminarization occurred. For the forward portion of the pressure surface, predictions with a relaminarized model and data gave heat transfer rates exceeding fully turbulent values for some cases.

The lag equation for $\mathrm{P}^{+}$gave reasonahle agreement with data. A lag equation for either $A^{+}$or $K^{\text {w was sus- }}$ ceptible to giving physically unrealistic results, due to the extreme variability of these quantities near the stagnation point
Neglecting freestream turbulence effects on laminar heat transfer always underpredicted the pressure surface heat transfer. The $k-\infty$ model. described by ('linat [1s]. predieted loading edge Frossling numbers near one. The effects of freestream turbulence on leading edge heat transfer were not seen with the $k$ - w model. ('onsequently. this model on average underpredicted pressure side heat transfer. But for some cases this model overpredicted the heat transfer. Where the model overpredicted the heat transfir it was raused by transition occurring closer to the leading edge than was seen in the data. The $k-2$ model agreed better with data at high Reymolds numbers.

The models presented here can "asily be incorporated into a a threedimensional Vavier-Stokes code. These results show that if $K$ is maintained at a level of approximately $4 \times 10^{-6}$. 1 he pressure surfare is likely. to be laminar. Pressure surfaces that appeared laminar were seen for exit Reynolds numbers approaching one million. Rotor Reynolds numbers in this range are representative of those in the high pressure turbine. The benefits of designing blades with pressure surface relaminarization are dependent on the local turbulence level. Wrothods for predicting the effects of both turbulence level and scale on heat transfer are needed to be able to reliably quantify the benefits of relaminarization.

The Smitli and huethe[19] nodel for accounting for the efferts of freestrean turbulence is helpful to the heat transfer predictions, but it is incomplett. For exalliple. it does not account for the effects of turbulences scale. Turbulence scale has been shown by Vanfossen et al. [28] among others to affect stagnation region heat transfer. Infortunately, the length scale is not always available along with the heat transfer data. Dullenkopf and Mayle[29] proposed that the effective turbulence intensity account for the blockage, velocity gradient. Reynolds number. as well as the turbulence intensity. Dullenkopf and Mayle[30] proposed a method to include? the effect of turbulence scale. Heat transfer predictions in the non-turbulent region would be improved if a correlation similar to that of Simith and Kuetle. but incorporating the factors mentioned, was developed.

The analysis tended to overpredict the suction surface heat transfer in the laminar region. while at times underpredicting the pressure surface laminar region heat transfer. It appears that better agreement with dat a would be achieved using the Steelant and Dick[11] model for the variation of $T u$ with freestream velocity. But. the Steelant and Dick relaminarization model underpredicted heat transfer more than the other relaminarization models. This could be due to its influence on the prediction of transition start. 


\section{References}

[1] Zhang. L.. and Han. J.-C'.. 1994. "Influence of Main-

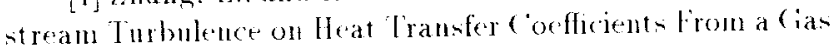
"lurbine Blade." ASME Joumal of Heat Thonsfer. Vol. 116. pp. $8996-902$.

[2] Brown, A.. and Martin. B.W., 1982. "Flow Transi-

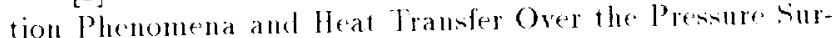
facen of cias Turbine Blades," ASBLE Jounnel of Engine ring for Pouer Vol. 104, pp. 3601-367.

[3] Nicholson. I.H. Forest, A.E.. Oldfield, M.L. (i.. and Sicluliz. D,L.. 1984. "Heat Transer Optimized Turbine Blades-An Experincutal study lising Transient Terhnicues." ASME Journal of Engmering for reas Tublime and Poucr. Vol. 106. ple. 173-181.

[4] ceneci. T., and smith, A.M.O. 1974. Analysis of Turbulent Boundary Layers. Academic Press. N.S.

[5] Crawford. M.E. and Lays. W.... 1976. "ST.LSA Progran for Numerical ('omputation of Two-Dimensional Internal and External Boundary Laver Flown." NASA C R2742.

[6] Kays. W.M. and (rawford. M.F... 1981). "Consertive Heat and Mass Transfer." hecond Edition. McrirawHill. Sew York.

[7] Mayle, R.E... 1991. "The Role of Laminar-l'urbulent Transition in (ias Turbine Engines." ASME Journal of Turbomachinery. Vol. 113. pp. 509-537.

[8] Boyle. R..l. and Simon. F.F.. 1999. "Mach Number Effects on Turbine Blade Transition Length Prediction." ASNE Journal of Turbomachinery. Vol. 121. pp. 694-702.

[9] Solomon. W.I.. Walker. (i.J.. and Gostelow, I.P.. 1995 "Transition Length Prediction For Flows With Rapidy Changing Pressure Graslients", ASME paper 95-('T-241.

[10] Dunham. I. 1972. "Predictions of Boundary Layer Transition on Turbomachinery Blades." A(iARD-AC-164.

[11] Steelant. I. and Dick, E., 1999 "Prediction of ByPass Transition By Means of a Turbulence Weighting Factor - Part 1: Theory and Validation," ASME paper 99-(iT-29.

[12] Chima, R.V.. 1987 "Explicit Multigrid Algorithm for Quasi-Three- Dimensional Flows in Turbomachinery." AIAA Journal of Propulsion and Pouer. Vol. 3. No. 5, pp. $397-405$.

[13] Chima. R.V.. and Vokota, I.W., 1990. "Numerical Analysis of Three-Dimensional Viscous Internal Flows," A A A lournal Vol. 28. No. 5. pp. 798-806.

[14] Arnone. A.. Liou. M.-S., and Povinelli. L. A., 1992. "Navier-Stoker Solution of Transonic Cascade Flows I'sing Non-Periodic ('-Type Cirids." AIA Journal of Propulsion and Pouer. Vol. 8. No. 2. pp. 410-417.

[15] Sorenson. R.L., 1980. "A Computer Program to Generate Two-Dimensional (irids About Airfoils and Other Shapes by the Lse of Poisson s Equation." NASA TM 81198.

[16] Chima. R.V.. Giel, P.W., and Boyle. R.J.. 1993. "An Algebraic Turbulence Model for Three-Dimensional Viscous Flows." AAIA paper 93-0083. (NASA TM-105931).
[17] Ameri. A.A. and Arnone. A.. L992 "Yavier-Stokes Heat Transfer Predictions l'sing Two-lequation Turbulence ("losures," MlA t paper 92-3067.

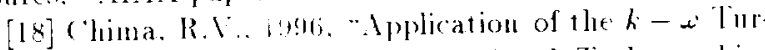
bulence Model to Quasi-Tliree-Dinensional Turbomarhincry Flows." MAA Journal of Propulsion and Pourer. Vol. 12. No. 6. pp. 1176-1179.

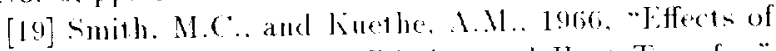
Turbulence on Laminar Skin Friction and Heat Tramser." Physics of Fluids. Vol. 9. pp 23:37-2344.

[20] Arts. T.. Duboute, J.-M.. and Rollin. (i.. I998, "Aero-Thermal Performance Measurenents aud Analysis of a Two-Dimensional High Turning Rotor Blade." ASME. Journal of Turbomachinery. Vol. 120, 1']. 494-499.

[21] Blair. M.F.. 1983. "Influence of Free-titrean Turbulence on Turbulent Boundary Layer Heat Transer and Nean Profile Development. Part 11-Analysis of Results." ASMlE Journal of Heat Trander. Vol. 105. Pp. 41-4T

[2:2] Arts. T.. lambert de Rourroit. M.. and Rutherford. A.W. 1990. "Atro-Thermal Investigation of a Highly loaded Tramonic Limear Turbine Ginde Vane cascade." Vhi Techuical tote 17.

[23] Dring. R.P.. Blair. M.F.. Joslyn. H.D.. Power. (i.D. and Verdon. I.N. 1986. "The Effects of Inlet Turbulence and Rotor/stator Interactions on the Aerodynamics and Heat Transfer of a Large-Scale Rotatiug Turbine Model - I-Final Report." NASA ('R 4079.

[24] Ciel. P.M., Van Fossen. (i.J.. Boyle. R..1.. Thurman. D.R, and ("ivinskas. K.C. 1999. "Blade Heat Transfer Meannrements and Predictions in a Transonic Turbine ('ascade." ASIIE paper 99-6iT-125.

[25] Giel. P.M.. Bunker. R.S. Van Fosenen, G.J.. and Boyle. R.J.. 2000). "Heat Transfer Measurements and Predictions on a Power (ieneration (ias Turbine Blade." ASMF paper $2000-(i T-209$.

[26] Blair. M.F. 1994. "An Experimental Study of Heat Transfer in a Large-Sicale Turbine Rotor Passage." ASME Jounal of Turbomachinery. Vol. 116. pp. 1-13.

[2i] C'hima. R.Y, 1991. "Viscous Three-Dimensional Calculations of Transonic Fan Performance." AGARD Propulsion and Energetics Symposium on Computational Fluid Mechanics for Propulsion. San Antonio. TX. May 2i31 .

[28] VanFossen, (X.J.. Simoneau. R.J., and Ching. C.Y.. 1995. "Influence of Turbulence Parameters. Reynolds Number, and Body Shape on Stagnation-Region Heat Transfer." ASNE Journal of Heat Transfer. Vol. 117. pp. $59 \overline{-}-603$. also NASA TP 3487.1994.

[29] Dullenkopf, K. and Mayle, R.E..1994. "The Effects of Incident Turbulence and Moving Wakes on Laminar Heat Transfer in (ias Turbines," ASME Joumal of Turbomachinery. Vol. 116, pp. 23-28.

[30] Dullenkopf, K. and Mayle. R.E..1995. "An Account of Free-Stream- Turbulence Length Scale on Laminar Heat Transfer." ASME Journal of Turbomachinery. Vol. 11T, pp. $401-406$. 
Public reporting burden for this collection of information is estimated to average 1 hour per response. including the time for reviewing instructions, searching existing data sources, collection of information, including suggestions for reducing and reviewing the collection of information. Send comments regarding this burden estimate or any other aspect of this Davis Highway. Suite 1204, Arlington. VA 22202-4302, and to the Otfice of Management and Budgers Services, Directorate for Intormation Operations and Feports. 1215 Jefferson Davis highway. Suite 1204, Arlington. VA 22202-4302, and to the Office of Management and Budget, Paperwork Reduction Project (0704-0188), Washington, DC 20503.

\begin{tabular}{l|l|l|} 
1. AGENCY USE ONLY (Leave blank) & 2. REPORT DATE & 3. REPORT TYPE AND DATES COVERED
\end{tabular}

4. TITLE AND SUBTITLE September 2001

Technical Memorandum 5. FUNDING NUMBERS

Prediction of Relaminarization Effects on Turbine Blade Heat Transfer 6. AUTHOR(S)

WU-708-28-13-00

R.J. Boyle and P.W. Giel

7. PERFORMING ORGANIZATION NAME(S) AND ADDRESS(ES)

National Aeronautics and Space Administration

John H. Glenn Research Center at Lewis Field

Cleveland. Ohio 44135-3191

8. PERFORMING ORGANIZATION REPORT NUMBER

$\mathrm{E}-12832$

9. SPONSORING/MONITORING AGENCY NAME(S) AND ADDRESS(ES)

National Aeronautics and Space Administration

Washington. DC 20546-0001

10. SPONSORING/MONITORING AGENCY REPORT NUMBER

NASA TM-2001-210978

2001-GT-0162

11. SUPPLEMENTARY NOTES

Prepared for the 2001 Turbo Expo cosponsored by the American Society of Mechanical Engineers and the International Gas Turbine Institute, New Orleans, Louisiana, June 4-7, 2001. R.J. Boyle, NASA Glenn Research Center and P.W. Giel, QSS Group. Inc., 2000 Aerospace Parkway, Brook Park, Ohio 44142. Responsible person, R.J. Boyle. organization code $5820,216-433-5889$.

12a. DISTRIBUTION/AVAILABILITY STATEMENT

Unclassified - Unlimited

Subject Category: 34

Distribution: Nonstandard

Available electronically at http://g|trs, grc, nass.uov/GLTRS

This publication is available from the NASA Center for AeroSpace Information. 301-621-0390.

13. ABSTRACT (Maximum 200 words)

An approach to predicting turbine blade heat transfer when turbulent flow relaminarizes due to strong favorable pressure gradients is described. Relaminarization is more likely to occur on the pressure side of a rotor blade. While stators also have strong favorable pressure gradients, the pressure surface is less likely to become turbulent at low to moderate Reynolds numbers. Accounting for the effects of relaminarization for blade heat transfer can substantially reduce the predicted rotor surface heat transfer. This in turn can lead to reduced rotor cooling requirements. Twodimensional midspan Navier-Stokes analyses were done for each of eighteen test cases using eleven different turbulence models. Results showed that including relaminarization effects generally improved the agreement with experimental data. The results of this work indicate that relatively small changes in rotor shape can be utilized to extend the likelihood of relaminarization to high Reynolds numbers. Predictions showing how rotor blade heat transfer at a high Reynolds number can be reduced through relaminarization are given.

\section{SUBJECT TERMS}

Turbine heat transfer

15. NUMBER OF PAGES

transfer

\begin{tabular}{|c|c|}
\hline $\begin{array}{c}\text { 17. SECURITY CLASSIFICATION } \\
\text { OF REPORT } \\
\text { Unclassified }\end{array}$ & $\begin{array}{c}\text { 18. SECURITY CLASSIFICATION } \\
\text { OF THIS PAGE } \\
\text { Unclassified }\end{array}$ \\
\hline
\end{tabular}

\begin{tabular}{|c|c|}
\hline & $\begin{array}{l}\text { 15. NUMBER OF PAGES } \\
23 \\
\end{array}$ \\
\hline & 16. PRICE CODE \\
\hline $\begin{array}{l}\text { 19. SECURITY CLASSIFICATION } \\
\text { OF ABSTRACT } \\
\text { Unclassified }\end{array}$ & 20. LIMITATION OF ABSTRACT \\
\hline
\end{tabular}



